\title{
Hidrocefalia poshemorrágica asociada a la prematuridad: evidencia disponible diagnóstica y terapéutica
}

\author{
C. Bravo; P. Cano*; R. Conde**; M. Gelabert***; P. Pulido****; B. Ros***** y P. Miranda**
}

Servicios de Radiodiagnóstico y *****de Neurocirugía. Hospital Carlos Haya. Málaga. *Servicio de Neurocirugía. Hospital Vall d’Hebron. Barcelona. **Servicio de Neurocirugía. Hospital La Fe. Valencia. ***Servicio de Neurocirugía. Hospital Universitario de Santiago de Compostela. ****Servicio de Neurocirugía. Hospital de La Princesa - Hospital Montepríncipe. Madrid.

\section{Resumen}

La hemorragia de la matriz germinal y la hidrocefalia poshemorrágica son las complicaciones neuroquirúrgicas más frecuentes en los pacientes recién nacidos pretérmino ${ }^{91}$. La incidencia de estas complicaciones es muy variable según las series consultadas ${ }^{19,36,47,56,61,71,93}$, pero su prevalencia está en cualquier caso en aumento debido tanto a la mayor incidencia de embarazos múltiples y partos prematuros en relación al avance de las nuevas técnicas de fertilización, como a la mayor supervivencia de estos pacientes merced a los recientes avances en los cuidados perinatales ${ }^{85}$. En este contexto resulta esencial disponer de un conocimiento preciso y concreto de las recomendaciones diagnósticas y terapéuticas en referencia a esta entidad. Sin embargo, la evidencia disponible al respecto es a menudo fragmentada e incompleta. El objetivo de la presente revisión es proporcionar un resumen actualizado de los principales aspectos diagnósticos y terapéuticos de la hidrocefalia poshemorrágica asociada a la prematuridad. Para ello se ha solicitado a los miembros del grupo de trabajo de Neurocirugía Pediátrica de la Sociedad Española de Neurocirugía que revisen las cuestiones más relevantes en referencia a esta patología. Esto supone el primer paso para la elaboración de una guía clínica común para el tratamiento de las complicaciones asociadas a la hemorragia intra y periventricular del prematuro.

PALABRAS CLAVE. Hidrocefalia. Hemorragia intraventricular. Prematuridad. Tratamiento.

Posthemorrhagic hydrocephalus in the preterm infant: current evidence in diagnosis and treatment

\section{Summary}

Intraventricular haemorrhage and posthemorrhagic hydrocephalus are the most important neuro-

Recibido: 16-03-11. Aceptado: 8-05-11. logical complications in preterm infants during the neonatal period ${ }^{91}$. The prevalence of germinal matrixintraventricular haemorrhage widely varies depending on the population of study ${ }^{19,36,47,56,61,71,93}$, but it is in any case increasing due both to the higher incidence of multiple and preterm deliveries as well as the longer survival of preterm infants favoured by recent advances in perinatal care ${ }^{85}$. It is therefore of the utmost convenience to be familiar with the most important clinical evidence regarding this entity. However, the available evidence is often incomplete and piecemeal. The objective of the present review is to summarise the main diagnostic and therapeutic points regarding preterm-related posthemorrhagic hydrocephalus. The participants of the working-group in Pediatric Neurosurgery of the Spanish Society of Neurosurgery were asked to write these recommendations down. This hopefully represents the first step towards the definition of a clinical guide in the treatment of complications related to periventricular hemorrhage of the preterm infants.

KEY WORDS. Hydrocephalus. Intraventricular hemorrhage. Preterm infants. Treatment.

\section{Introducción}

La hemorragia de la matriz germinal característica de la prematuridad es una entidad relativamente infrecuente en términos absolutos ${ }^{19,36,47,56,61,71,93}$. Sin embargo, su prevalencia ha aumentado recientemente en nuestro medio de forma considerable. Ello es debido, por un lado a las nuevas técnicas de fertilización que han generado un mayor número de embarazos múltiples con el consiguiente incremento de partos prematuros. Por otra parte, el progreso experimentado por las unidades de cuidados intensivos neonatales ha permitido que la mayor parte de estos pacientes sobrevivan al periodo perinatal ${ }^{85}$. En este nuevo escenario resulta necesario conocer con precisión las recomendaciones de tratamiento en relación a las complicaciones asociadas a la hemorragia periventricular del prematuro, y en especial a la hidrocefalia poshemorrágica. 
En la presente revisión se analizan algunas de las cuestiones más relevantes relacionadas con esta entidad. En lo referente a las pruebas de imagen, se considera esencial la información proporcionada por la ecografía cerebral, tanto en términos de diagnóstico como de seguimiento. En lo que respecta al tratamiento conservador se abordan las principales cuestiones en relación a las medidas de tratamiento farmacológico y a las medidas de diversión transitoria de LCR. Finalmente, en relación al tratamiento quirúrgico, se intenta clarificar cuál es el momento adecuado para la implantación de una derivación definitiva de LCR, y qué papel juegan la profilaxis antibiótica, la técnica quirúrgica y la elección de un determinado sistema de derivación. El contenido de la revisión se ha segmentado en preguntas concretas de evidente aplicación práctica. Este artículo de revisión conjunta del grupo de trabajo de Neurocirugía Pediátrica de la Sociedad Española de Neurocirugía pretende ser el primer paso en la elaboración de un protocolo conjunto en el tratamiento de esta patología, particularmente compleja.

\section{Bloque I. Diagnóstico por la imagen}

1. ¿Cuál es la prueba de imagen de elección en el diagnóstico de la hemorragia intra y periventricular asociada a la prematuridad? ¿Cómo se clasifica?

La ecografía es un método de imagen no invasivo e inocuo, que no utiliza radiación ionizante ni precisa seda- ción, que puede realizarse de forma portátil e inmediata en las unidades de cuidados intensivos neonatales y que además permite estudios repetidos. Todas estas características, junto con su sensibilidad y precisión en la valoración de la dilatación ventricular, hacen de la ecografía la técnica de imagen de elección en el estudio de la hidrocefalia posthemorrágica (HPH) en el prematuro, frente a otras técnicas como la TC o la RM ${ }^{1,55,69,75}$. El estudio ecográfico clásico consiste en la exploración del contenido intracraneal con ecografía en escala de grises a través de la fontanela anterior, en planos coronal y sagital ${ }^{31}$. Este estudio básico se puede complementar con el uso del Doppler color y Doppler pulsado que proporcionan información sobre la hemodinamia e hidrodinamia cerebral ${ }^{13} \mathrm{y}$ con la utilización de otras vías de abordaje como la fontanela posterior, la posterolateral o mastoidea ${ }^{18}$, que es muy útil para la valoración de la fosa posterior, o incluso el agujero magno ${ }^{84}$.

La clasificación empleada clásicamente en la valoración de la hemorragia de la matriz germinal ha sido la de Papile y colaboradores ${ }^{56,57}$. En ella se definen cuatro grados según la extensión y localización de la hemorragia (Tabla 1).

Otros autores, como Volpe ${ }^{92}$ han establecido clasificaciones similares. Como medidas generales, la determinación de la presencia de sangre en la matriz germinal se efectúa preferentemente en registros coronales mientras que la sangre intraventricular se aprecia mejor en las imágenes parasagitales. En esta clasificación la presencia de infarto hemorrágico periventricular recibe una distinción específica al no considerarla simplemente una extensión de

Tabla 1

Clasificación de la hemorragia de matriz germinal según Papile y colaboradores ${ }^{56,57}$

\begin{tabular}{|l|l|}
\hline Gravedad & Descripción \\
\hline Grado I & Hemorragia de matriz germinal limitada al área caudotalámica \\
\hline Grado II & Extensión intraventricular sin dilatación ventricular \\
\hline Grado III & Dilatación del sistema ventricular subyacente, lleno de sangre \\
\hline Grado IV & Existencia de infarto hemorrágico venoso parenquimatoso asociado \\
\hline
\end{tabular}

Tabla 2

Clasificación ecográfica de la hemorragia intraventricular y de la matriz germinal (según Volpe ${ }^{92}$ )

\begin{tabular}{|l|l|}
\hline Gravedad & Descripción \\
\hline Grado I & $\begin{array}{l}\text { Hemorragia de matriz germinal con hemorragia intraventricular mínima }(<10 \% \text { del área ventricular) o } \\
\text { ausente }\end{array}$ \\
\hline Grado II & Hemorragia intraventricular moderada (10-50\% del área ventricular) \\
\hline Grado III & Hemorragia intraventricular grave $(>50 \%$ del área ventricular $)$ \\
\hline $\begin{array}{l}\text { Distinción } \\
\text { específica }\end{array}$ & Localización y extensión de la hiperecogenicidad periventricular \\
\hline
\end{tabular}




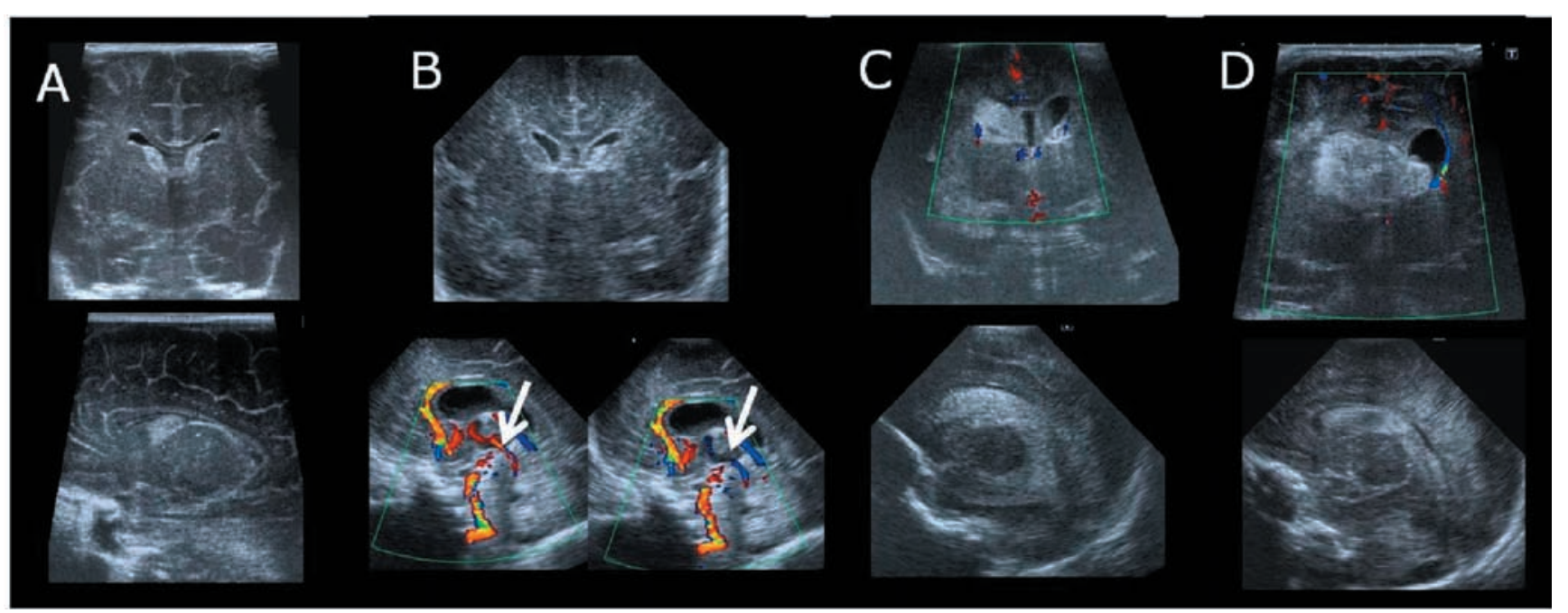

Figura 1. Imágenes coronales y sagitales-parasagitales a través de fontanela anterior. A: Hemorragias subependimarias bilaterales. B: Sangrado intraventricular con coágulo ventrículo lateral izquierdo, engrosamiento del epéndimo por ependimitis química, y señal doppler rojo-azul en acueducto de Silvio. C: Sangrado intraventricular masivo que provoca una dilatación aguda del ventrículo lateral derecho. D: Sangrado intraventricular masivo con infarto venoso periventricular parieto-occipital derecho.

la hemorragia de la matriz germinal o intraventricular.

\section{2. ¿Puede la ecografía proporcionar un diagnóstico} precoz de la hidrocefalia poshemorrágica en estos pacientes?

La ecografía desempeña varios papeles en el estudio del niño con HPH. No solamente sirve para el diagnóstico, sino que además permite detectar niños en riesgo de desarrollar una HPH, valorar la gravedad una vez que se ha producido la dilatación ventricular, contribuir a la decisión de tratar o no, y evaluar la respuesta al tratamiento. Antes del desarrollo de los síntomas clínicos de hidrocefalia (aumento del perímetro cefálico, diástasis de suturas, signos de hipertensión intracraneal...) la ecografía realizada dentro del protocolo del RNPT (recién nacido pretérmino) permite por una parte detectar a los niños en riesgo de desarrollar una hidrocefalia, es decir niños con hemorragia de la matriz germinal-intraventricular (HMG-HIV), y por otra, diagnosticar la dilatación del sistema ventricular de forma precoz. La probabilidad de desarrollar una hidrocefalia aumenta con la gravedad del sangrado (fig. 1), de forma que en las hemorragias graves con sangrado intraventricular masivo, que dilata los ventrículos, y las que llevan asociado un infarto venoso periventricular la probabilidad de desarrollar una HPH es del 55\% y $80 \%$ respectivamente ${ }^{74}$.

La detección de hemorragia en el espacio subaracnoideo puede contribuir a predecir el desarrollo de hidrocefalia ${ }^{27} \mathrm{y}$ esto es especialmente útil en aquellos niños con sangrados más leves, que precisarán seguimientos más estrechos. A veces el diagnóstico se hace por asimetría en el tamaño o la ecogenicidad entre cisternas simétricas o surcos cerebrales, o bien porque se objetiven directamente coágulos en el espacio extra-axial (en cisterna magna) (fig. 2). La sensibilidad es baja, pero la especificidad llega a ser de hasta el $93 \%{ }^{32}$.

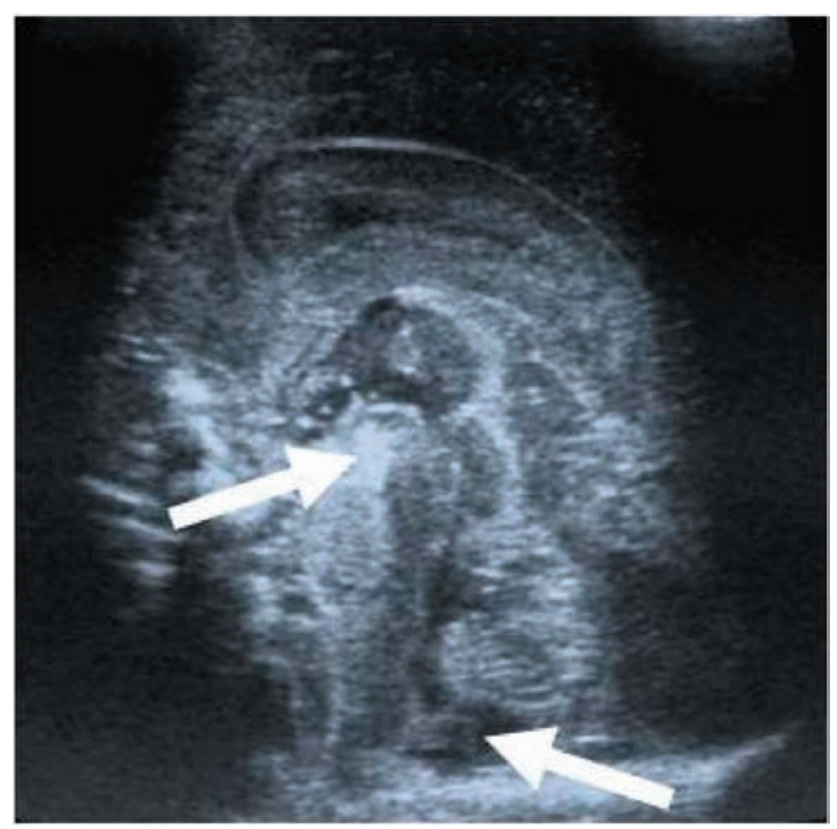

Figura 2. Corte en línea media sagital a través de fontanela anterior que muestra una marcada ecogenicidad de la cisterna interpeduncular (flecha), por la existencia de sangrado subaracnoideo (este hallazgo es más fiable sobre todo si se dispone de un estudio basal normal) y coágulo en cisterna magna (flecha). 


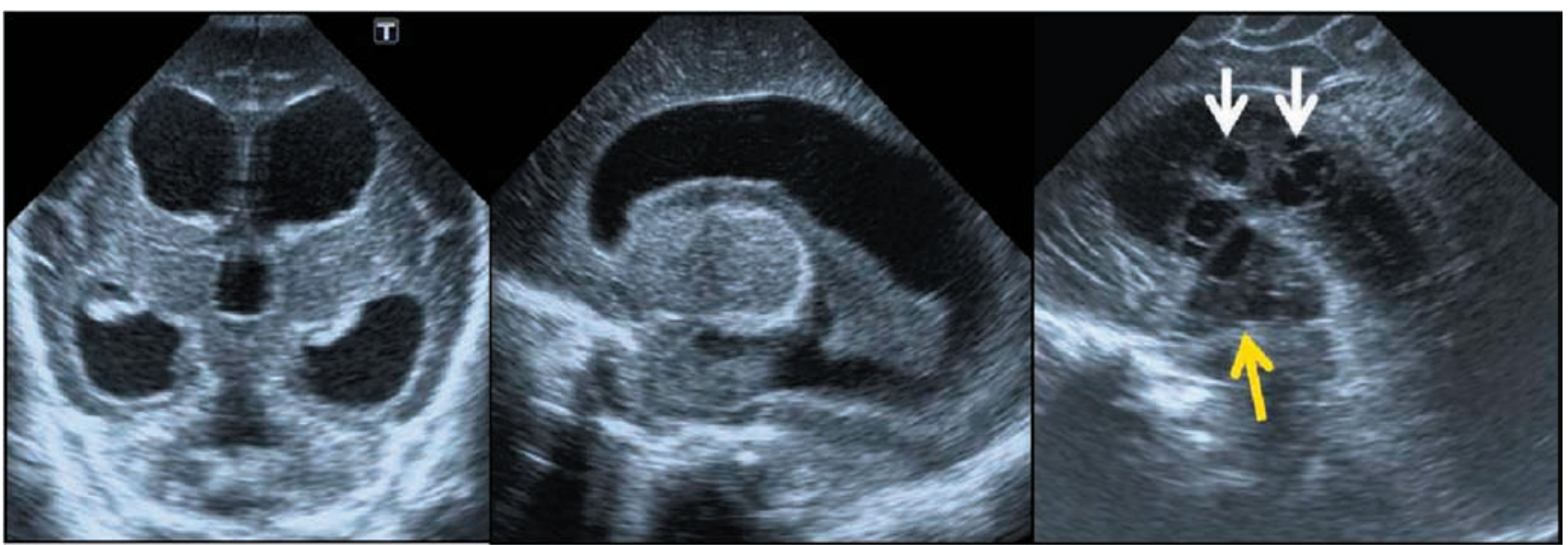

Figura 3. Imagen coronal a través de fontanela anterior que muestra una dilatación redondeada de las astas frontales, dilatación de las astas temporales, del tercer y cuarto ventrículos. Imagen parasagital que presenta la dilatación del ventrículo lateral, con un coágulo con forma de molde en su interior. Imagen en línea media con fenestraciones en el septum pellucidum (áreas redondeadas anecoicas en el septum pellucidum, debajo de cuerpo calloso).

3. ¿Qué entidades deben tenerse en cuenta en el diagnóstico diferencial de la hidrocefalia poshemorrágica del prematuro?

Una vez detectada la dilatación ventricular, la ecografía permite hacer el diagnóstico de HPH frente a otras causas de aumento del tamaño ventricular, valora su gravedad, el lugar de la obstrucción, y puede ayudar a tomar la decisión de tratar o no la hidrocefalia.

En la hidrocefalia el aumento de tamaño de los ventrículos laterales incluye las astas temporales, que son fácilmente identificables, se produce un redondeamiento de las astas frontales y un abombamiento del receso anterior del tercer ventrículo. En ocasiones se pueden detectar fenestraciones en el septum pellucidum y frecuentemente signos del sangrado intraventricular, como pueden ser coágulos, niveles líquidos o engrosamiento e irregularidad del epéndimo por ependimitis química (fig. 3).

El diagnóstico diferencial fundamental es con la ventriculomegalia ex-vacuo, debida a atrofia, en cuyo caso el aumento de tamaño de los ventrículos laterales no lleva asociado el abombamiento de las astas frontales ni la dilatación de astas temporales, y la superficie ventricular suele ser irregular y festoneada, debido a la pérdida de parénquima subyacente (fig. 4). Con frecuencia la dilatación del sistema ventricular en niños prematuros lleva asociado un componente mixto, de hidrocefalia obstructiva y atrofia.

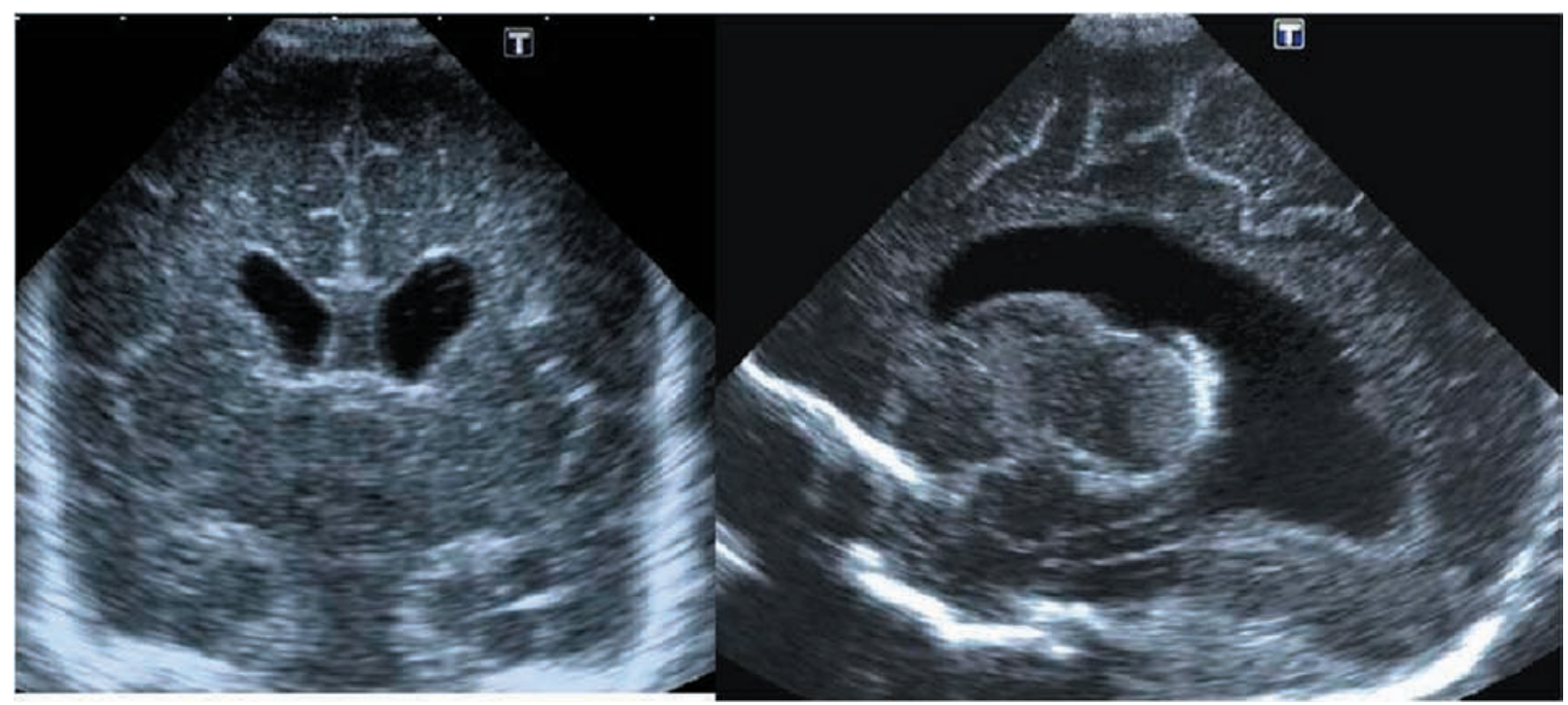

Figura 4. Imágenes coronal y parasagital a través de FA, con ventriculomegalia sin dilatación de astas temporales y superficie festoneada o irregular del ventrículo lateral. 


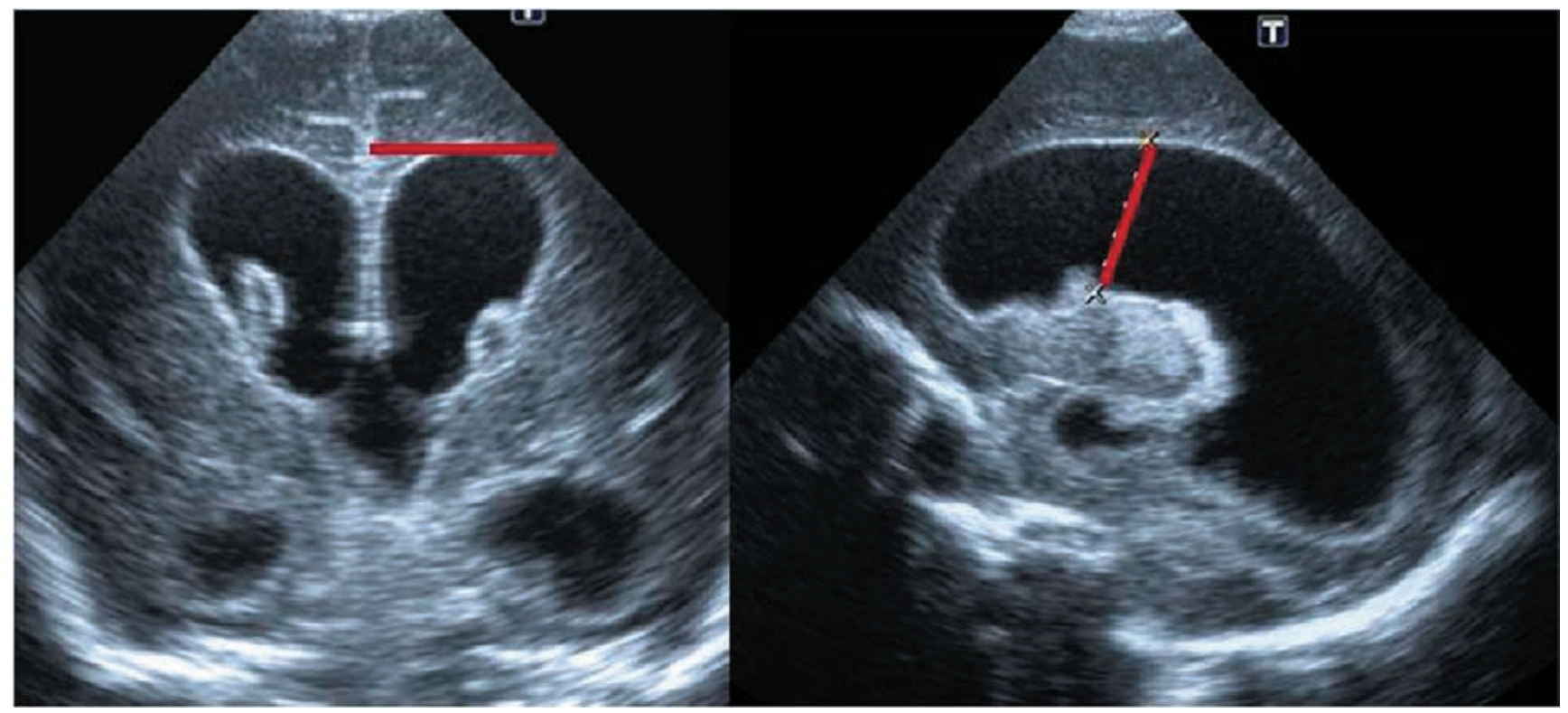

Figura 5. Corte coronal a la altura de los agujeros de Monro: medida de la anchura del asta frontal (índice de Levene). Corte parasagital: medida de la anchura del ventrículo lateral a nivel de la hendidura-caudotalámica.

\section{4. ¿Cuáles son los principales indicadores de la grave- dad y la progresión de la hidrocefalia?}

Para hacer objetiva la gravedad de la hidrocefalia y poder determinar su progresión, es necesario medir el tamaño de los ventrículos. No hay establecida una medida estándar del tamaño ventricular, depende de los distintos autores y de los distintos centros. Uno de los índices más utilizados es el índice ventricular de Levene ${ }^{38}$ que mide la distancia entre la hoz interhemisférica y el borde externo del ventrículo lateral en un corte coronal a través de la fontanela anterior, a la altura del agujero de Monro. Según este índice se considera el tratamiento de la hidrocefalia cuando la distancia está $4 \mathrm{~mm}$ por encima del percenti $^{197}$. Otros autores ${ }^{48,68}$ utilizan la medida de la distancia caudotalámica, o índice caudotalámico, que se obtiene en un corte parasagital a nivel del cuerpo del ventrículo lateral, en una imagen a través de la fontanela anterior. La distancia medida va desde la hendidura caudotalámica hasta la pared superior del ventrículo. Según este índice la dilatación es leve si la medida está entre $5-10 \mathrm{~mm}$, moderada entre $10-15 \mathrm{~mm}$ y grave cuando es mayor a $15 \mathrm{~mm}$ (fig. 5). Hay otras formas de medir el sistema ventricular mucho menos utilizadas, como son entre otras la medición de la distancia tálamo-occipital o la anchura total de astas frontales. La medida utilizada en el estudio inicial, o basal, es la que debe utilizarse en los estudios de seguimiento.

\section{5. ¿Puede la ecografía diagnosticar con precisión la obs- trucción al flujo normal de LCR a esta edad?}

La ecografía puede permitir una caracterización precisa de la hidrocefalia en términos de obstrucción intra- ventricular, extraventricular o presencia de cavidades atrapadas: para ello resulta muy útil la evaluación de la fosa posterior a través de la fontanela mastoidea y el estudio Doppler color. La dilatación del sistema ventricular supratentorial con cuarto ventrículo normal indica obstrucción en acueducto de Silvio. Si la dilatación incluye al cuarto ventrículo, con obliteración o ausencia de cisterna magna, la obstrucción está a nivel de los agujeros de salida del cuarto ventrículo. Cuando la dilatación afecta a todo el sistema ventricular y la cisterna magna está presente o aumentada la obstrucción es extraventricular (fig. 6). La dilatación aislada o mayor de un ventrículo, por ejemplo el cuarto ventrículo, indica atrapamiento del mismo (fig. 7).

La ecografía Doppler color nos permite ver la permeabilidad del acueducto de Silvio o de las salidas del cuarto ventrículo. Para poder obtener un efecto Doppler que muestre el movimiento del LCR a través del acueducto o del sistema ventricular, es necesario que existan partículas en LCR (células sanguíneas o detritus). Aunque a veces es posible detectar este movimiento de forma espontánea existen maniobras provocadoras como puede ser la compresión de la fontanela, del abdomen o el propio llanto del niño ${ }^{107}$ (fig. 8) .

\section{6. ¿Qué información aporta el estudio en modo Doppler?}

El estudio Doppler de los vasos intracraneales puede proporcionar información sobre la presión intracraneal. Cuando la presión intracraneal sobrepasa la presión de perfusión cerebral existe una dificultad al flujo sanguíneo cerebral, afectando inicialmente a la fase diastólica del ciclo 


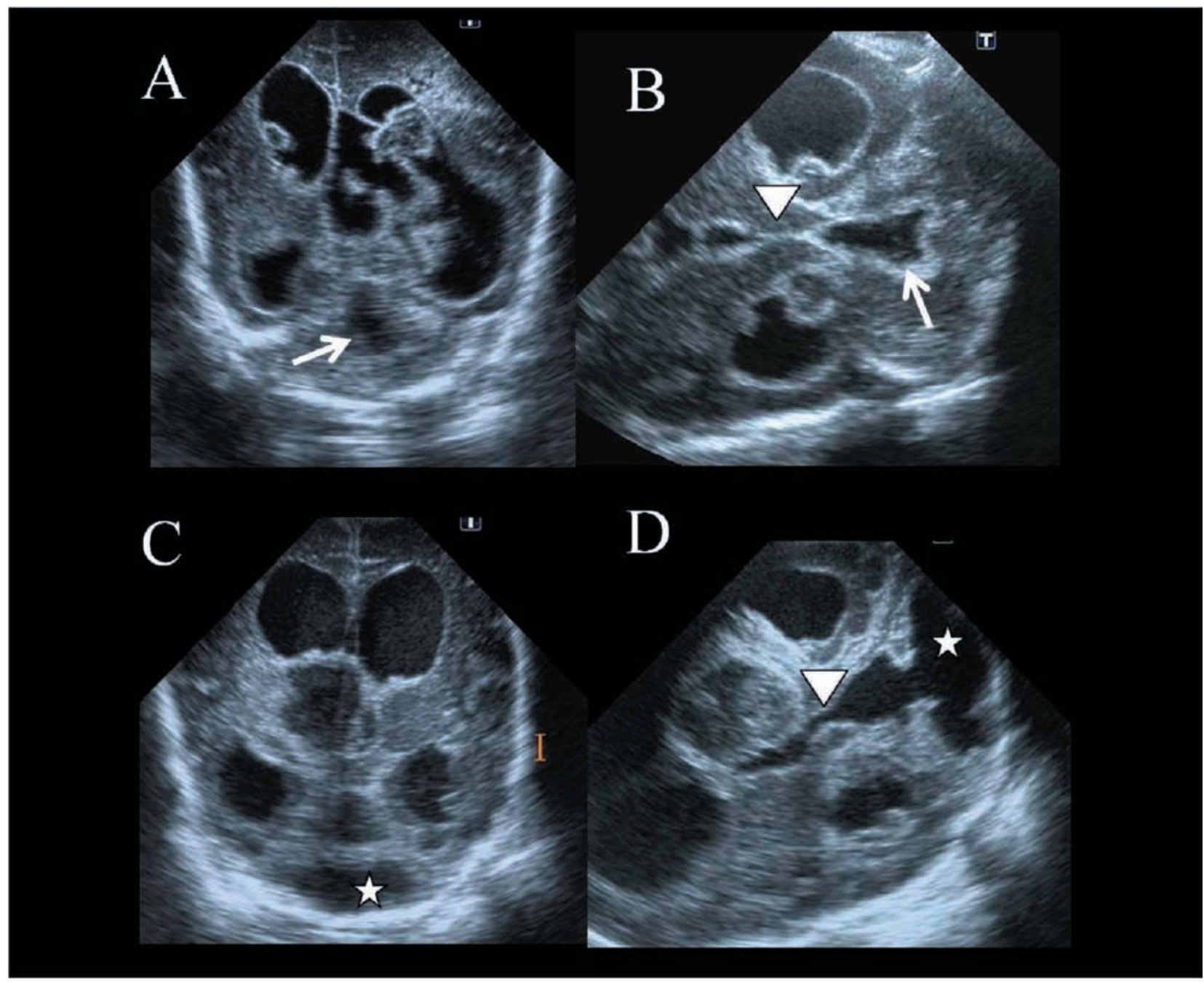

Figura 6. Hidrocefalia intraventricular e hidrocefalia extraventricular. A) imagen coronal a través de la fontanela anterior y B) imagen axial oblicua a través de fontanela mastoidea: Dilatación del sistema ventricular incluido el cuarto ventrículo con obliteración de la cisterna magna. Existen restos de coágulos en ventrículos laterales y un marcado engrosamiento del epéndimo, más evidente en cuarto ventrículo. El acueducto de Silvio está obliterado. C) imagen coronal a través de fontanela anterior y D) imagen axial oblicua a través de fontanela mastoidea en un niño con un gran hematoma evolucionado en área talámica derecha. Dilatación de todo el sistema ventricular, con acueducto de Silvio dilatado y gran comunicación entre cuarto ventrículo y cisterna magna quistica. Flecha blanca: cuarto ventrículo). Cabeza de flecha: acueducto de Silvio. Estrella: cisterna magna.

cardíaco. Esta alteración queda reflejada en una elevación del índice de resistencia (IR) de los vasos intracraneales. El índice de resistencia es un parámetro que relaciona la velocidad del flujo sanguíneo cerebral en la sístole (velocidad pico sistólica) y en la diástole (velocidad telediastólica). El estudio Doppler intracraneal suele realizarse en la arteria cerebral anterior o en una arteria pericallosa, que son vasos fácilmente accesibles desde la fontanela anterior. La medida del IR proporciona una información indirecta de la presión intracraneal ${ }^{20}$. Así en un niño con hidrocefalia, un IR aumentado por encima de valores normales es indica- tivo de aumento de la presión intracraneal. Deben excluirse otras causas de aumento del IR como la persistencia del ductus arterioso ${ }^{89}$ (fig. 9).

En un niño con hidrocefalia con IR basal dentro de límites normales, la aplicación de una pequeña presión en la fontanela anterior, o test de compresión de la fontanela ${ }^{82,83}$, permite detectar niños con alteración grave de la compliance intracraneal y en riesgo de desarrollar hipertensión intracraneal (HTIC). En estos casos la compresión de la fontanela provoca una alteración en el volumen intracraneal que se traduce en un aumento de presión. Los niños con 


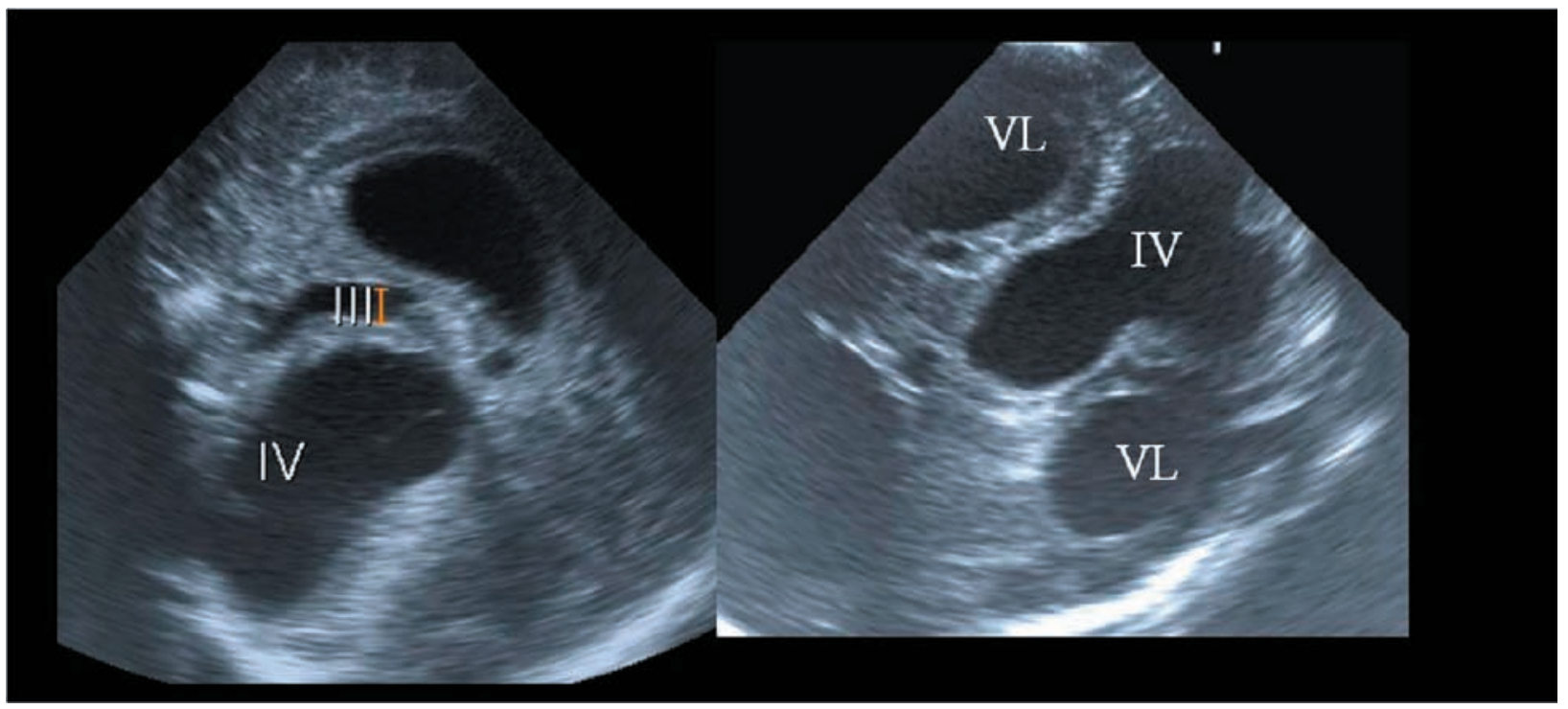

Figura 7. Imagen sagital de línea media a través de fontanela anterior e imagen coronal oblicua de fosa posterior a través de fontanela mastoidea: Gran dilatación del cuarto ventrículo (IV) que desplaza anteriormente al tercer ventrículo (III) y que se hernia cranealmente a través del tentorio. Astas occipitales dilatadas (VL).

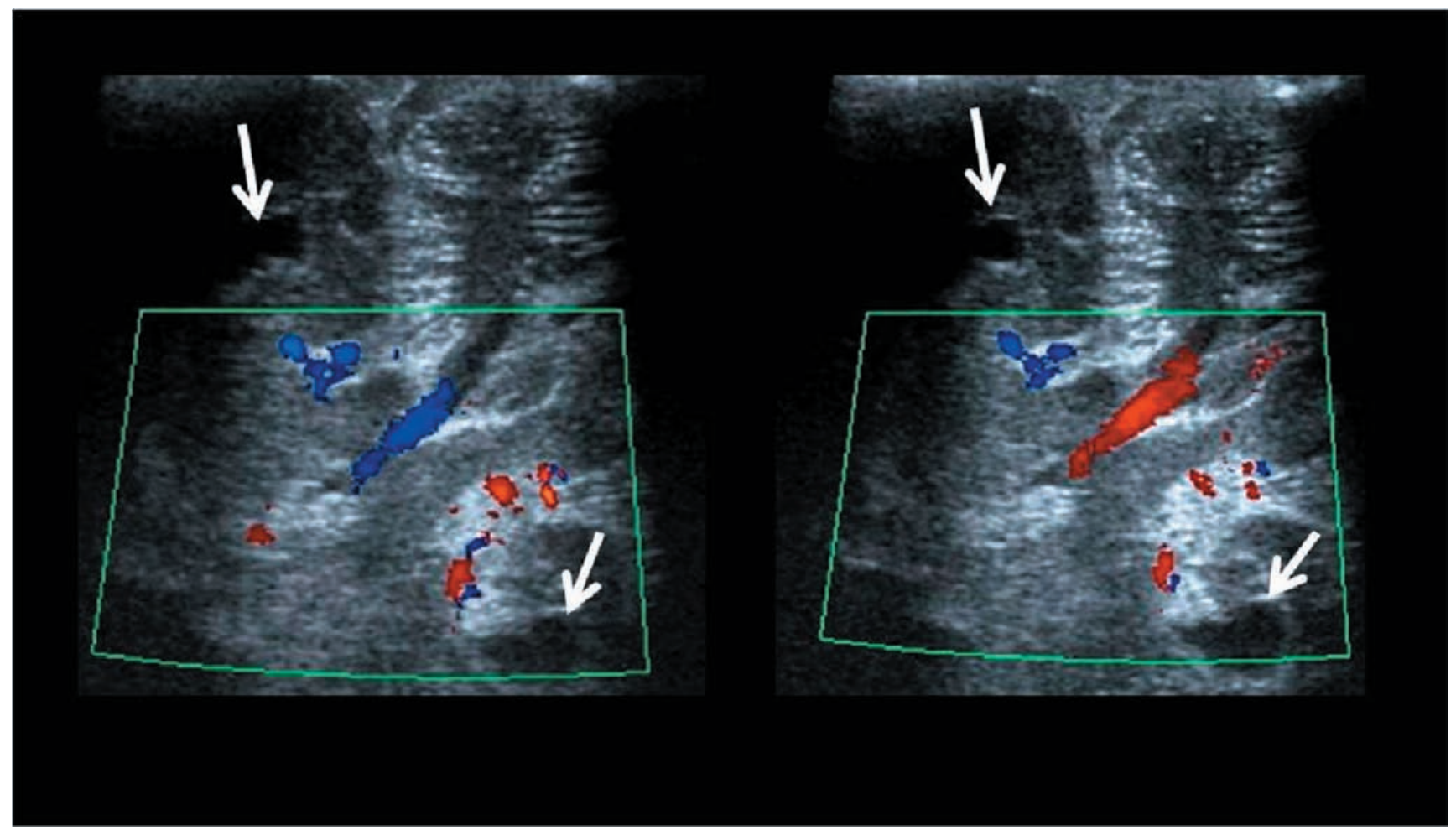

Figura 8. Imágenes axiales oblícuas a través de fontanela mastoidea, con ecografía doppler color. La señal de color rojoazul alternantes en el acueducto de Silvio indica permeabilidad del mismo. Flechas blancas: astas occipitales dilatadas.

capacidad de adaptación (reserva) compensarán este aumento de presión y no modificarán su IR de forma significativa. Sin embargo en los casos en los que los mecanismos de compensación ya están utilizados (compliance muy alterada), el aumento de presión provocado por la compresión de la fontanela, no podrá ser compensado y producirá un aumento del IR. En el estudio de Taylor y Madsen ${ }^{83}$ los niños que necesitaron una derivación ventricular habían 


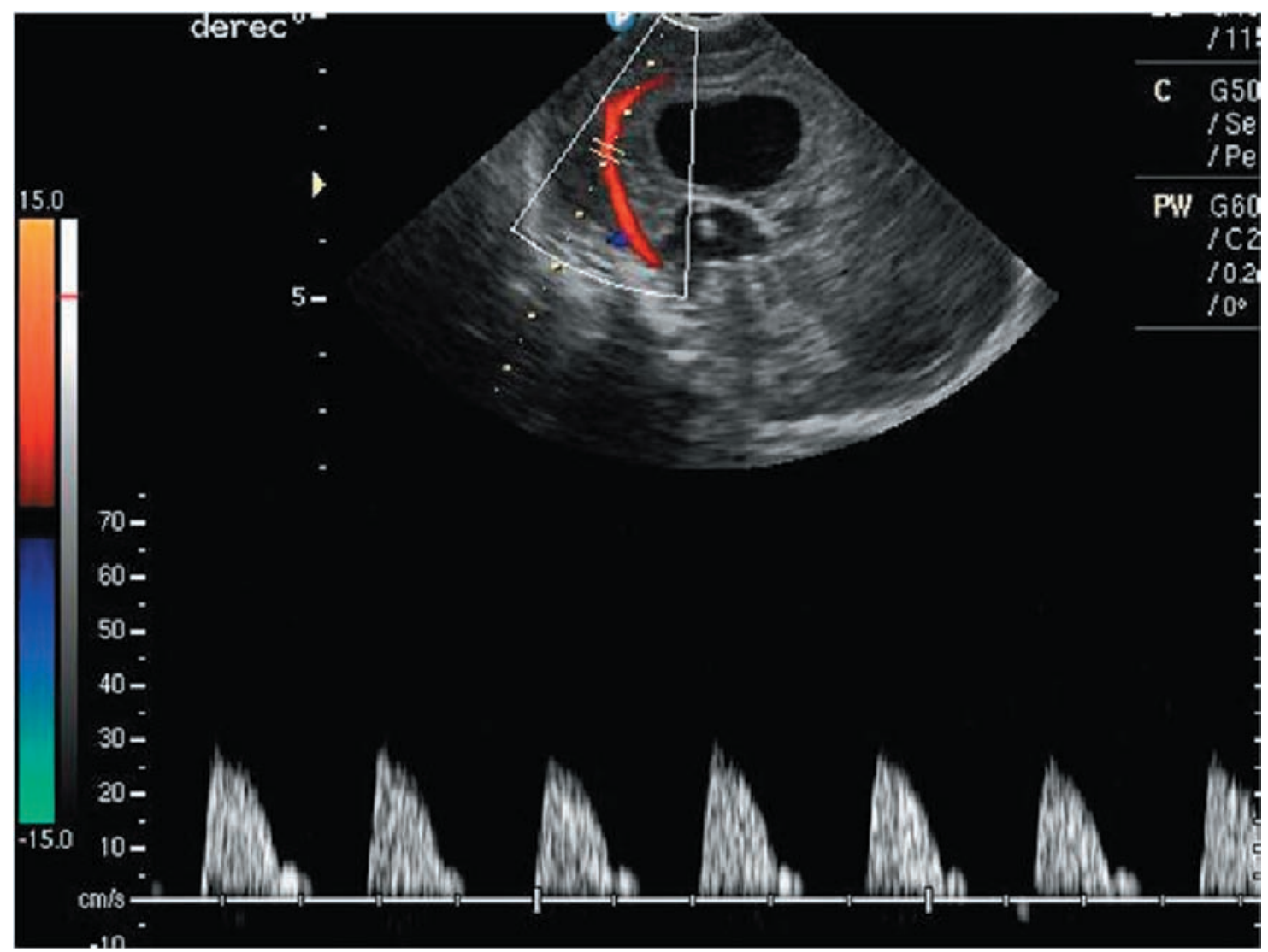

Figura 9. Estudio Doppler de la arteria cerebral anterior, que muestra un patrón espectral con ausencia de diastoles. El indice de resistencia está elevado.VPS $=30 \mathrm{~cm} / \mathrm{s} ; V T D=0 ; I R=1$. IR=(VPS-VTD) $/ V P S$. (VPS: velocidad pico sistólica; VTD: velocidad telediastólica; IR: Índice de resistencia).

mostrado un incremento del IR, tras la compresión de la fontanela, igual o mayor al $45 \%$, mientras que en los que no necesitaron tratamiento quirúrgico el incremento del IR había sido menor al $18 \%$.

El test de compresión de la fontanela puede ayudar a determinar si un niño con dilatación ventricular mixta, con componente de obstrucción y de atrofia, se beneficiará o no de una derivación del LCR. Si tras aplicar la compresión el IR se incrementa, indica que predomina el componente obstructivo en la dilatación ventricular, y el niño se puede beneficiar de la derivación.

\section{7. ¿Es útil la ecografía también en el seguimiento de} estos pacientes una vez derivados?

Una vez que se ha implantado una derivación ventricular, la ecografía permite valorar la eficacia del tratamiento y algunas de sus complicaciones. El primer hecho que demuestra la efectividad del tratamiento es la normalización del índice de resistencia ${ }^{52}$, antes incluso que la disminución del tamaño ventricular, que es el otro dato indicativo de la eficacia de la derivación. Mientras el niño tiene las fontanelas permeables la ecografía puede ser utilizada para el seguimiento y la detección del mal funcionamiento del shunt. El catéter es una estructura tubular ecogénica y con frecuencia es posible localizar su posición con ecografía. (fig. 10). Otras complicaciones como tabicaciones y septos del sistema ventricular, ventriculitis, meningitis o colecciones extraaxiales también pueden ser diagnosticadas ecográficamente (fig. 11).

\section{8. ¿Cuáles son las principales limitaciones de la ecografía en esta entidad?}

La limitación fundamental de la ecografía es la incapacidad para detectar precozmente la lesión parenquimatosa secundaria a la hidrocefalia, sobre todo de la sustancia blanca, cuya prevención, junto con la disminución de la presión intracraneal, es el objetivo fundamental del tratamiento. En este sentido las nuevas técnicas de resonancia magnética (RM) como RM difusión, tensor de difusión, espectroscopia y la RM funcional podrán contribuir en el futuro próximo a caracterizar mejor estos aspectos. Sin embargo, la necesidad de trasladar a los pacientes a las unidades de RM y el mayor tiempo de exploración limitan su uso $49,108$. 


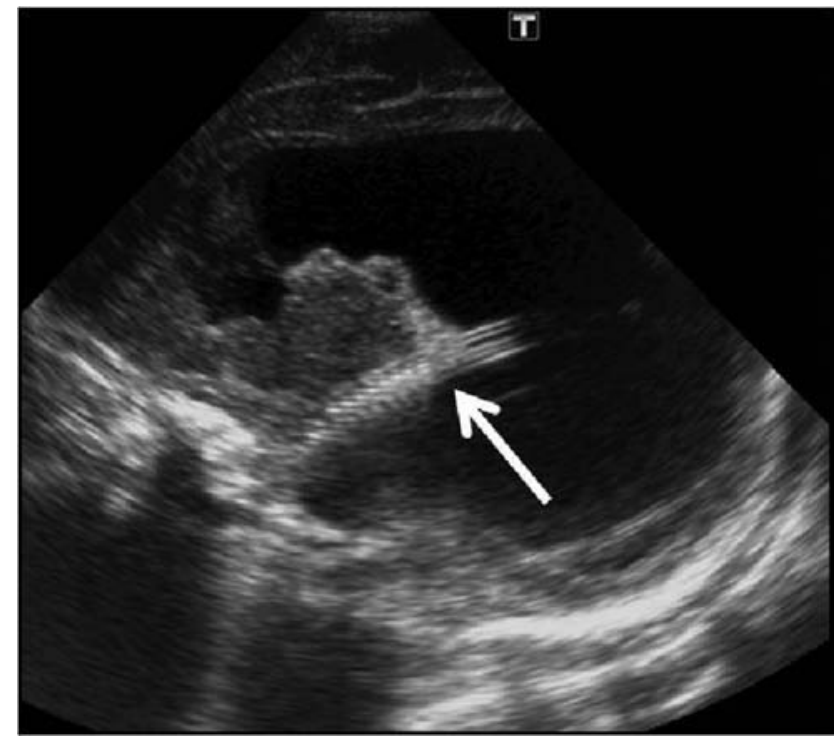

Figura 10. Imagen parasagital a través de la fontanela anterior que muestra el catéter (flecha) en el asta temporal del ventrículo lateral.

\section{Bloque II. Medidas farmacológicas de tratamiento}

\section{9. ¿Existe un tratamiento médico eficaz para el con-} trol de la hidrocefalia poshemorrágica asociada a la prematuridad?

Las hemorragias del prematuro grado III y IV de Papile desarrollan en más de un $50 \%$ de los casos una hidrocefalia secundaria ${ }^{40,54,58,60}$. La hidrocefalia se produce por obstrucción de las vías habituales de reabsorción y circulación del LCR por restos hemáticos y detritus ${ }^{92}$. La sangre produce además una aracnoiditis química y reacción fibrótica, principalmente en las cisternas de la fosa posterior. Para evitar el desarrollo de la hidrocefalia se han utilizado diversos tratamientos médicos:

9. a. Acetazolamida y furosemida. Producen una disminución de la producción de LCR. Asocian efectos secundarios importantes como las alteraciones en el equilibrio ácido-base, trastornos hidroelectrolíticos, alteraciones gastrointestinales, nefrocalcinosis y letargia ${ }^{72}$.

Whitelaw ${ }^{100}$ realizó una revisión sobre la utilización de estos fármacos y concluyó que no podían ser recomendados en prematuros, por las múltiples complicaciones que pueden producir y porque no reducen la probabilidad de precisar sistemas de derivación permanente de LCR. En un estudio posterior, Kennedy y colaboradores ${ }^{33}$ ratificaron estas conclusiones y hoy su uso no se recomienda salvo condiciones especiales.

9. b. Agentes fibrinoliticos intraventriculares. Estudios experimentales con agentes fibrinolíticos intraventriculares han mostrado una disminución de la dilatación ventricular secundaria a la hemorragia, por lo que también se ha ensa-

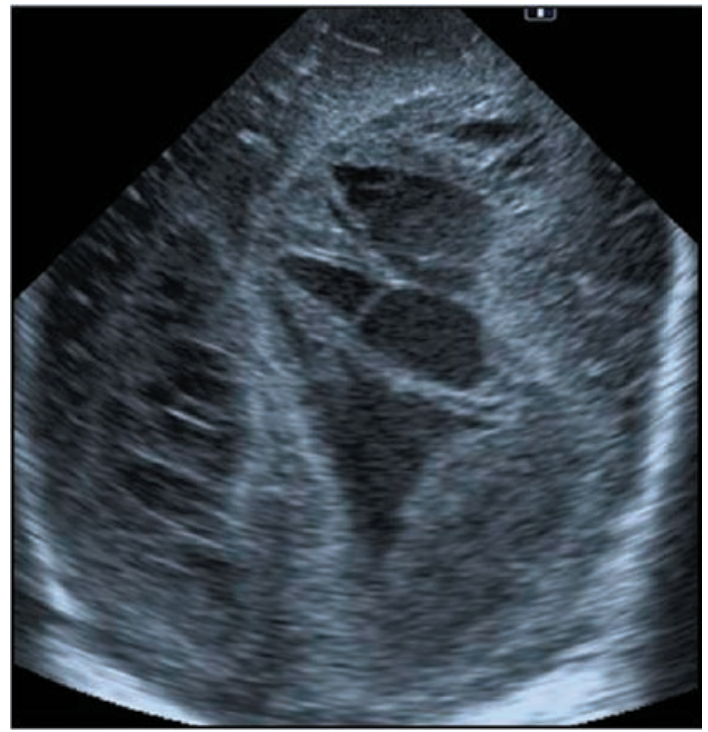

Figura 11. Ventriculitis. Corte coronal oblicuo posterior a través de la fontanela anterior. Imagen del cuerpo de ambos ventrículos laterales, dilatados de forma asimétrica y con múltiples septos y loculaciones de contenido ecogénico.

yado su aplicación en neonatos. En un revisión sistemática para la Colaboración Cochrane, Whitelaw ${ }^{99}$ analizó la evidencia disponible respecto a esta modalidad de tratamiento concluyendo que la necesidad de derivación permanente fue la misma en los grupos de tratamiento respecto a los controles. El tratamiento con fibrinolíticos intraventriculares ha mostrado además en series aisladas un riesgo aumentado de resangrado ${ }^{43}$.

Sin embargo, Whitelaw y colaboradores ${ }^{102}$ describieron una nueva modalidad terapéutica en 2003 utilizando como tratamiento fibrinolítico el activador tisular del plasminógeno r-TPA, combinado con drenaje e irrigación de LCR (terapia DRIFT): una dosis de $0,5 \mathrm{mg} / \mathrm{kg}$ de r-TPA es inyectada en un catéter ventricular frontal y posteriormente se irriga con una solución artificial de LCR a $20 \mathrm{ml} / \mathrm{h}$., permitiendo el drenaje de líquido por un catéter implantado en el ventrículo contralateral. La irrigación se mantiene durante 72-96 horas. Los autores realizaron este tratamiento en un grupo de 24 pacientes: uno falleció y, de los restantes, 6 precisaron derivación definitiva de LCR. El índice de infección fue del $8 \%$ y en 2 pacientes se produjo una nueva hemorragia. Los autores consideran que se trata de un tratamiento altamente agresivo e invasivo pero con menor incidencia de desarrollo de hidrocefalia hipertensiva. Estos mismos autores publicaron más recientemente una revisión de un grupo de niños tratados con esta terapia frente a un grupo sin tratamiento, con dos años de seguimiento y confirmaron un mejor desarrollo cognitivo en los pacientes tratados con la terapia DRIFT ${ }^{104}$. 


\section{Bloque III. Drenaje temporal de LCR}

\section{0. ¿Qué papel tienen los métodos de drenaje temporal de LCR en la hemorragia periventricular del lactante?}

Ante la inoperatividad de las medidas farmacológicas para conseguir prevenir de forma eficaz la necesidad de la implantación de una derivación ventriculoperitoneal (DVP) tras la hidrocefalia poshemorrágica en el lactante, diversas medidas de drenaje temporal de LCR se han ensayado como alternativas conservadoras de tratamiento.

10. a. Punciones lumbares de repetición. El papel de las punciones evacuadoras de LCR fue inicialmente evaluado por el Ventriculomegaly Trial Group ${ }^{87,88}$ mediante ensayos clínicos bien diseñados, que no encontraron un factor protector en la punción de repetición de LCR frente a la probabilidad de requerir un sistema de derivación permanente de LCR. Debe señalarse que en estos ensayos se iniciaban las punciones lumbares a partir de la primera tras la hemorragia. Series no controladas posteriores ${ }^{22,50}$ encontraron un efecto beneficioso cuando estas medidas se instauraban de forma más precoz. Estas medidas se asociaron también a un incremento en el número de infecciones de $\mathrm{LCR}^{6,79}$. Whitelaw ${ }^{98}$ analizó en 2001 para la Colaboración Cochrane de forma sistemática el papel de las punciones lumbares de repetición en los neonatos con hemorragia intraventricular y no encontró una disminución en la necesidad posterior de derivación permanente de LCR, si bien las punciones se asociaron a un mayor número de complicaciones infecciosas. Shooman y colaboradores revisaron esta misma materia en 2009 y confirmaron las conclusiones descritas: las punciones lumbares de repetición aumentan la probabilidad de complicaciones infecciosas y no disminuyen la probabilidad de requerir una derivación permanente de $\mathrm{LCR}^{73}$.

10. b. Punciones ventriculares de repetición. Las punciones ventriculares ${ }^{22,24,76}$ se han usado en el tratamiento de la hidrocefalia ya que permiten una mayor extracción de líquido que las punciones lumbares. Este procedimiento tiene un bajo índice de complicaciones, en particular cuando la punción es guiada con ecografía. Permite disminuir el tamaño ventricular en más de un $50 \%{ }^{39}$ en términos volumétricos. Sin embargo, el meta-análisis mencionado de Whitelaw ${ }^{98}$ concluyó que no existían diferencias estadísticamente significativas al compararlo con el tratamiento conservador respecto a la probabilidad de requerir una válvula definitiva, evidenciando sin embargo un aumento en el número de complicaciones infecciosas.

10. c. Drenaje ventricular externo (DVE). La derivación transitoria de LCR mediante DVE ha sido descrita como una medida segura y eficaz en diferentes series retrospecti$\operatorname{vas}^{5,28,67}$. Sin embargo, la principal complicación asociada a esta medida de tratamiento es el desarrollo de infecciones de LCR que pueden resultar devastadoras ${ }^{22}$. La revisión de Shooman y colaboradores ${ }^{73}$ pone de relieve que se trata de una medida que no ha sido evaluada mediante ensayos bien diseñados y que puede resultar útil como medida temporal en el control de la hidrocefalia extremando las medidas de prevención infecciosa y el cuidado de la asepsia y el funcionamiento del drenaje.

10. d. Derivación ventrículo-subgaleal. Al igual que en el caso de los drenajes externos, no existen estudios bien diseñados que hayan evaluado el papel de las derivaciones ventriculo-subagaleales como medida de tratamiento conservador. La información que tenemos proviene de series retrospectivas con recomendaciones tanto a favor ${ }^{37,78,105}$ como en contra de su uso ${ }^{63}$, debido nuevamente a la alta tasa de complicaciones infecciosas asociadas.

10. e. Reservorios ventriculares. La principal ventaja de estos sistemas radica en que las tasas de infección reportadas son menores que las observadas en los casos de DVE y derivaciones ventriculosubgaleales ${ }^{29,45}$. El uso de estos sistemas podría permitir alcanzar unas mejores condiciones del LCR y de la situación clínica del paciente lo que a su vez podría traducirse en una menor tasa posterior de malfunciones de la derivación permanente ${ }^{29}$. Por este motivo ha sido recomendada como medida transitoria de tratamiento ${ }^{73}$.

\section{Bloque IV. Elección del momento de la derivación perma- nente de LCR.}

11. ¿Es la derivación permanente de LCR la única medida de tratamiento eficaz cuando se ha instaurado la hidrocefalia?

Tal y como se ha señalado anteriormente, los tratamientos farmacológicos y los métodos de derivación transitoria de LCR no disminuyen la necesidad de implantar un sistema de derivación definitivo de LCR cuando la hidrocefalia se ha instaurado tras la hemorragia inicial ${ }^{7,97,101}$. No obstante, estas modalidades temporales de tratamiento pueden permitir controlar la hipertensión intracraneal del paciente y facilitar el tránsito a un escenario clínico en el que la cirugía de derivación definitiva sea más segura y esté expuesta a una menor tasa de complicaciones.

La ventriculostomía premamilar endoscópica ha mostrado un bajo porcentaje de éxito en el tratamiento primario de la hidrocefalia posthemorrágica, aunque sin embargo constituye una alternativa a la revisión valvular tras disfunción e incluso podría ser el tratamiento de elección en estos $\operatorname{casos}^{59}$. Algunos autores han publicado porcentajes elevados de éxito de ventriculostomía endoscópica tras punciones repetidas de reservorio si se seleccionan pacientes con valores de TGF- $\beta 1$ (transforming growing factor beta-1) en LCR por debajo de un determinado umbral indicativo de hiporeabsorción ${ }^{42}$. No hay que olvidar, además, que existe controversia respecto a la indicación de ventriculostomía premamilar endoscópica por debajo 
del año de vida por el porcentaje elevado de fallos de tratamiento descritos, incluso en casos más favorables como es la hidrocefalia por estenosis acueductal.

En cualquier caso, por norma general y como consecuencia de los efectos de la hemorragia, la fibrosis de granulaciones aracnoideas, la aracnoiditis adhesiva de la fosa posterior o la obstrucción a nivel del acueducto de Silvio convergen en la instauración de una hidrocefalia permanente que persiste a pesar de la utilización de medidas de control transitorias y frente a la cual la derivación ventrículo-peritoneal de LCR puede constituir la única opción de tratamiento efectivo definitivo ${ }^{7}$.

\section{2. ¿Cuál es el momento más adecuado para la implan- tación de una derivación ventrículo-peritoneal?}

El factor determinante más importante parece ser el peso corporal del paciente en el momento de la intervención, como expresión de la condición de la piel y plano subcutáneo del paciente, de cara a minimizar complicaciones quirúrgicas como dehiscencia de la piel, decúbitos del sistema valvular o catéteres y fístula de $\mathrm{LCR}^{7,46,81,103,106}$. Diversos estudios reflejan un porcentaje tolerable de complicaciones en pacientes intervenidos a partir de los 1400-1500 gr de peso, cifra que podría tomarse como umbral mínimo necesario para la intervención ${ }^{7}$. Es importante señalar que en muchos estudios aparece el peso del paciente al nacimiento, que no corresponde necesariamente con el peso que tiene en el momento del desarrollo de la hidrocefalia, pues en muchos casos ésta aparece de forma diferida y progresiva, ni con el peso en el momento de la intervención. El otro factor importante que recoge la literatura es el de las características del LCR, en especial la cantidad de restos hemáticos, dado que la concentración de proteínas parece menos importante ${ }^{11}$. El aclaramiento del LCR podría justificar el empleo de medidas transitorias, en especial el uso de dispositivos de acceso ventricular, dado que la derivación ventrículo-subgaleal o técnicas de DRIFT parecen tener un porcentaje excesivo de complicaciones ${ }^{103,105,106}$. Algunos autores no tienen en cuenta las características del LCR de cara a la planificación quirúrgica y el porcentaje de fallo valvular por obstrucción por restos hemáticos es bajo ${ }^{68}$. El éxito de técnicas de ventriculostomía endoscópica tras el aclaramiento del LCR está aún por determinar y, aunque algunos trabajos son prometedores en este sentido ${ }^{42,59}$, como regla general puede recomendarse la derivación ventrículo-peritoneal como primer tratamiento de pacientes pretérminos con hidrocefalia posthemorrágica y con un peso corporal en el momento de la intervención de 1400-1500 gr ${ }^{7}$. En pacientes por debajo de este peso en los que se estime que es necesario iniciar el tratamiento de la hidrocefalia, la medida más razonable sería la colocación de dispositivos de acceso ventricular para la realización de punciones evacuadoras repetidas, lo que además permitirá el aclaramiento del LCR si el neurocirujano estima importante este factor. Si la ganancia ponderal es rápida y adecuada y se estima que el paciente alcanzará el citado peso umbral en un plazo breve de tiempo, podría contemplarse la posibilidad de esperar, evitando la colocación de reservorios, empleando la punción lumbar o ventricular como medida puntual de control de la hipertensión intracraneal ${ }^{68}$.

\section{Bloque V. Profilaxis antibiótica en la implantación de la DVP.}

13. ¿Cuál es la incidencia de infección de la DVP en la hidrocefalia poshemorrágica asociada a la prematuridad?

La incidencia de infección de la derivación en la hidrocefalia poshemorrágica asociada a la prematuridad ha experimentado un descenso importante de acuerdo a los resultados de las principales series comunicadas que se resumen en la Tabla 3. La incidencia real es difícil de estimar, la información proviene de estudios observacionales ${ }^{9,10,41,66,80}$ y depende de múltiples factores como peso al nacimiento, antecedentes de procedimientos transitorios de derivación de LCR o profilaxis antibiótica empleada. En general se estima que la incidencia de infección de la derivación en este grupo de pacientes se sitúa alrededor del $10 \%$.

Tabla 3

Incidencia de infección de la DVP en prematuros con HPH

\begin{tabular}{|l|l|l|l|c|}
\hline \multicolumn{1}{|c|}{ Autor, año } & N & Diseño de estudio & Población de estudio & Incidencia de infección \\
\hline Boynton $^{9}, 1986$ & 50 & Retrospectivo, serie de casos & HPHP III-IV & $50 \%$ \\
\hline Bruinsma $^{10}, 2000$ & 39 & Retrospectivo, serie de casos & Prematuros & $33 \%$ \\
\hline Reinprecht $^{66}, 2001$ & 42 & Retrospectivo, serie de casos & HPHP & $7.1 \%$ \\
\hline Wellons $^{95}, 2009$ & 20 & Retrospectivo, multicéntrico & $\begin{array}{l}\text { HPHP III-IV y peso } \\
<1500 g \text { al nacimiento }\end{array}$ & $5 \%$ \\
\hline
\end{tabular}




\section{Tabla 4}

Relación entre HPH e infección de DVP por gram-negativos y anaerobios

\begin{tabular}{|l|l|l|l|}
\hline \multicolumn{1}{|c|}{ Autor, año } & N & Población de estudio & Patógenos \\
\hline Stamos $^{80}, 1993$ & 23 & $\begin{array}{l}2420 \text { casos hidrocefalia pediátrica, } \\
23 \text { infecciones DVP por gram- }\end{array}$ & $\begin{array}{l}\text { E. Coli } \\
\text { Klebsiella } \\
\text { Flora mixta }\end{array}$ \\
\hline Bruinsma $^{10,} 2000$ & 39 & Prematuros & $\begin{array}{l}90 \% \text { ECN y S. Aureus }<10 \% \\
\text { Enterococcus faecalis y enterobacteriaceae }\end{array}$ \\
\hline Arnell ${ }^{4}, 2008$ & 237 & 237 pacientes, 474 intervenciones & $\begin{array}{l}19 \text { ECN, } 7 \text { S. Aureus } \\
6 \text { Propionibacterium acnes }\end{array}$ \\
\hline
\end{tabular}

14. ¿Son los patógenos implicados en la infección del sistema diferentes en este grupo de edad?

La información referente a los patógenos implicados en la infección de la DVP en la HPH del prematuro deriva habitualmente de estudios más amplios en los que se evalúa ésta complicación en la población pediátrica en general $^{3,14,17,77}$, y si bien se hace referencia al hecho de que la HPH del prematuro presenta un mayor riesgo de desarrollar infección de la DVP, no se menciona que el espectro de patógenos sea significativamente diferente al del resto de la población pediátrica. Sin embargo, diversos estudios retrospectivos relacionan la $\mathrm{HPH}$ asociada a prematuridad con una mayor probabilidad de infección del sistema por gérmenes gram-negativos y anaerobios ${ }^{4,10,80}$ (Tabla 4).

\section{5. ¿Qué recomendaciones pueden establecerse respecto} a la profilaxis antibiótica en estos pacientes?

La conveniencia de la profilaxis antibiótica en la cirugía de la DVP ha sido evaluada mediante diversos ensayos randomizados y confirmada en estudios de meta-análisis ${ }^{25,64}$. La pauta antibiótica profiláctica se extiende habitualmente 24 horas tras la cirugía. Ratilal y colaboradores ${ }^{64}$ revisa- $^{-}$ ron en un meta-análisis reciente el papel de la profilaxis antibiótica en la cirugía de DVP: se revisaron 17 ensayos aleatorizados comprendiendo un total de 2.134 pacientes, con diversas pautas de profilaxis y sistemas de derivación. Los pacientes que recibieron profilaxis para derivaciones definitivas mostraron un índice significativamente menor de infección, independientemente del tipo de derivación implantada (peritoneal o atrial) y de la edad del paciente. El descenso en la probabilidad de desarrollar una infección tras emplear profilaxis antibiótica se cuantificó con un valor de OR de 0.51 (IC 95\% 0.36-0.73). Otros autores, sin embargo, conceden mayor importancia a detalles técnicos como la irrigación con suero impregnado con antibiótico o el cambio de guantes durante la cirugía ${ }^{65}$. En cualquier caso, no existe una pauta antibiótica específicamente recomendada, y se han publicado series que definen tasas acep- tables de infección con el uso tanto de ceftriaxona como con trimetroprim-sulfametoxazol en pacientes menores de 1 mes de vida ${ }^{51,94}$. La elección de una profilaxis concreta debe adaptarse en cada centro en función de la prevalencia de estafilococo meticilin-resistentes y de la incidencia de infecciones por flora mixta.

\section{Bloque VI. Técnica quirúrgica y tipo de derivación}

\section{6. ¿Es preferible una incisión craneal recta o curva a la hora de implantar la DVP?}

Respecto a las incisiones en piel, y teniendo en cuenta la fragilidad cutánea en estos pacientes, se recomienda practicar incisiones curvas (en semiluna a nivel craneal) con una disección adecuada que permita prevenir los decúbitos. Es particularmente importante preservar la capa de periostio como elemento protector del material de implantación. Si se opta por realizar incisiones rectas, éstas deberían ser lo suficientemente grandes para liberar la adherencia a planos profundos, anular tensiones y evitar que el material protésico quede inmediatamente bajo ellas?

\section{7. ¿Es preferible emplear un acceso ventricular frontal o parietal?}

Al ser la obstrucción proximal la causa más frecuente de fallo del sistema de derivación ${ }^{16,70}$, debe ponerse especial cuidado respecto a dónde queda finalmente colocada la punta del catéter ventricular. Habitualmente se consideran dos posibles puntos de entrada para la colocación del catéter ventricular: la frontal o pre-coronal y la parietal posterior.

Albright y colaboradores ${ }^{2}$ en un estudio observacional sobre 114 pacientes pediátricos, describieron que la duración de la función del catéter ventricular resultó significativamente mayor cuando se había empleado un acceso frontal, sin que se documentara un mayor número de infecciones respecto al acceso parietal. Esta observación es relevante ya que algunos autores han señalado que la 
inserción del catéter por vía frontal puede asociarse con un mayor número de incisiones, tiempo quirúrgico más prolongado y mayor tasa de infecciones del sistema. Sin embargo, un estudio aleatorizado comparando las dos entradas, frontal y parietal, concluyó que la inserción anterior del catéter no ofrecía ninguna ventaja respecto al acceso parietal, ya que el porcentaje de sistemas que persistió funcionante a los 14 meses de seguimiento fue del 59 y del $70 \%$ respectivamente ${ }^{8}$.

En algunas series, el acceso frontal se ha asociado con un riesgo aumentado de desarrollar crisis comiciales ${ }^{15}$, si bien esta observación no ha sido confirmada por otros autores en estudios similares, descriptivos y retrospectivos ${ }^{86}$.

Respecto a las consideraciones técnicas en el momento de la inserción del catéter, deben ser destacados algunos aspectos. En primer lugar, al introducir el catéter por la vía frontal el punto de entrada se sitúa a nivel frontal precoronal en la línea media pupilar, y la dirección ideal es perpendicular al cráneo. Puede resultar útil emplear catéteres en ángulo recto que previenen una movilización no deseada del catéter una vez introducido. La longitud del catéter no suele ser superior a los $4 \mathrm{~cm}$, y la sutura del catéter en el punto de salida para su fijación puede evitar también migraciones imprevistas. El agujero de trépano debe realizarse de forma muy cuidadosa para evitar presiones y hundimientos indebidos en un cráneo particularmente dúctil. La apertura dural debe ser lo más reducida posible ya que ello disminuirá el riesgo de fístula de LCR alrededor del catéter proximal.

Las referencias más habituales para el punto de entrada parietal son a $3 \mathrm{~cm}$ de línea media y 6 del inion. La dirección del catéter está dirigida hacia el canto interno del ojo ipsilateral. Pueden introducirse los primeros $3 \mathrm{~cm}$ con la ayuda del estilete y posteriormente avanzar $2 \mathrm{~cm}$ más el catéter libre, lo cual situará la punta de catéter en el asta frontal ipsilateral. Debe señalarse que se ha descrito un mayor número de catéteres con entrada parietal y posición subóptima o inadecuada con respecto a catéteres cuya entrada fue frontal ${ }^{23}$.

\section{8. ¿Pueden la ecografía o la endoscopia facilitar la introducción del catéter ventricular y disminuir así el número de obstrucciones proximales?}

La introducción manual del catéter ofrece como ventajas un menor tiempo quirúrgico y menor coste respecto al uso de un endoscopio, si bien la colocación se basa en referencias anatómicas más o menos constantes. La principal ventaja de utilizar un endoscopio durante la inserción del catéter ventricular radica en la posibilidad de conocer la trayectoria y situación final del catéter durante la intervención. A pesar de que inicialmente se contempló la posibilidad de que una colocación optimizada podría disminuir la tasa de obstrucciones proximales, el ensayo de inserción endoscópica de los sistemas de derivación (Endoscopic shunt insertion trial) no demostró incidencias de obstrucción proximal significativamente diferentes entre la inserción manual libre del catéter y la asistida por endoscopia ${ }^{34}$. La ecografía también ha sido utilizada como ayuda intraoperatoria en la implantación de los catéteres ventriculares, aunque no existe evidencia respecto al beneficio que pueda ofrecer en la disminución de complicaciones por desarrollo de obstrucción proximal ${ }^{96}$.

\section{9. ¿Qué precauciones deben tenerse en la tunelización del sistema? \\ El paso subcutáneo del sistema derivativo debe reali-} zarse con el menor número de incisiones auxiliares, idealmente en un solo trayecto. Se recomienda fijar el catéter proximal al sistema valvular con sutura no reabsorbible para evitar desconexiones así como para anclar el sistema y minimizar el riesgo de migraciones. Es imperativo realizar una cuidadosa disección de los planos en todo el trayecto para evitar una posición anormalmente superficial tanto de la válvula como del catéter, previniendo así la aparición de heridas por decúbito ${ }^{14,23}$.

\section{0. ¿Es preferible la introducción del catéter distal en abdomen por minilaparotomía? ¿de cuánta longitud?}

La introducción del catéter peritoneal bajo observación directa mediante mini-laparotomía disminuye los riesgos de perforación intestinal, de estructuras vasculares u otros órganos respecto a la introducción a ciegas por punción con trócar. El uso de laparoscopia en algunos casos puede facilitar la eliminación de bridas, situación nada infrecuente en pacientes prematuros que han presentado algún problema intestinal previamente, de forma paradigmática la enterocolitis necrotizante.

Un punto de controversia es la longitud de catéter peritoneal que se recomienda implantar en pacientes de bajo peso. La longitud exacta no está establecida, pero debe tenerse en cuenta que introducir entre 10 y $20 \mathrm{~cm}$ implica con alta probabilidad la necesidad de realizar una revisión quirúrgica para alargamiento del catéter entre los dos y cuatro años de edad. Couldwell y colaboradores ${ }^{12}$ recomiendan el uso de un catéter peritoneal extremadamente largo en el neonato $(120 \mathrm{~cm})$ : esta longitud no se asoció a un incremento en el número de complicaciones y sí obvia la necesidad de alargamiento posterior del catéter peritoneal durante el proceso de crecimiento del paciente.

\section{1. ¿Qué tipo de válvula puede recomendarse en estos pacientes?}

La relación entre el tipo de válvula y la obstrucción de la derivación también ha recibido una gran atención, debido en buena medida a las posibilidades de la industria de ofrecer nuevos sistemas y la necesidad de evaluar la 
seguridad y eficacia de los mismos.

Vinchon y colaboradores ${ }^{90}$ implantaron en 13 prematuros con hidrocefalia poshemorrágica y con un peso menor de 2000 gramos un sistema transitorio de drenaje ventriculoperitoneal sin válvula, previo a la implantación definitiva de la DVP. En comparación con los controles de su propia serie que recibieron tratamiento inicial con DVP, los pacientes con implantación de drenaje ventriculoperitoneal libre transitorio no presentaron mayores tasas de infección, aunque sí de obstrucción del sistema, si bien dichas diferencias no fueron estadísticamente significativas.

El estudio de referencia para evaluar el comportamiento de los sistemas valvulares en la práctica clínica es el ensayo randomizado publicado por Drake y colaboradores $^{16}$ en 1998 sobre el diseño de las válvulas en el manejo de la hidrocefalia pediátrica. En dicho ensayo se comparó de forma prospectiva, controlada y aleatorizada la tasa de supervivencia de tres sistemas valvulares diferentes: una válvula de presión diferencial convencional, una válvula de presión diferencial asociada a un dispositivo de retardo de sifonaje (Delta), y una válvula de control de flujo (OrbisSigma). Se reclutaron 344 pacientes entre 1 y 18 años con diversas etiologías respecto a su hidrocefalia, procedentes de 12 centros y con un seguimiento mínimo de un año. La supervivencia libre de fallo del sistema fue del $61 \%$ a los 12 meses y del $47 \%$ a los 2 años, sin que se evidenciaran diferencias estadísticamente significativas en el comportamiento de las válvulas estudiadas. Otros autores han confirmado estos hallazgos ${ }^{30}$. Sin embargo, Hanlo y colaboradores ${ }^{26}$ publicaron en 2003 un estudio observacional prospectivo con 5 años de seguimiento en el que trataron a 557 pacientes (la mitad niños) de hidrocefalia de diverso origen con una válvula de control de flujo (Orbis-Sigma). Los autores describen una supervivencia libre de fallo del sistema del $71 \%$ al año de seguimiento, recomendando su uso frente a los sistemas de presión diferencial.

La introducción de las válvulas programables ha supuesto un nuevo punto de interés ya que a priori la modificación de la presión de apertura podría traducirse en una menor incidencia de fracaso del sistema. En un estudio prospectivo randomizado sobre 377 niños con hidrocefalia, Pollack y colaboradores ${ }^{62}$ comunicaron una tasa de fracaso del sistema a los doce meses del $32 \%$ para la válvula programable (Hakim-Medos) frente al 39\% para las válvulas convencionales de presión diferencial, sin que estas diferencias resultaran estadísticamente significativas. Martinez-Lage y colaboradores ${ }^{44}$ han publicado una serie de 100 pacientes prematuros tratados con derivaciones programables (Polaris y Sophy) con una media de seguimiento de 55 meses: un $20 \%$ de los pacientes desarrollaron obstrucción del sistema proximal, mientras que sólo un $5 \%$ presentaron complicaciones infecciosas. Apoyados en estos resultados los autores concluyeron que las deriva- ciones programables analizadas resultaban tan seguras y eficaces como los dispositivos convencionales, haciendo mención expresa a que los ajustes externos de la presión de apertura aparentemente evitaron varias revisiones quirúrgicas en casos de disfunción del sistema. Por el contrario, Notarianni y colaboradores ${ }^{53}$ en una revisión retrospectiva sobre una serie de 253 pacientes con hidrocefalia pediátrica de los cuales 69 casos correspondían a hidrocefalias poshemorrágicas, no encontraron que el uso de derivaciones programables disminuyeran la tasa de obstrucciones o la necesidad de revisión de los sistemas de derivación. El uso de sistemas de derivación de presión diferencial asociados a dispositivos de retardo del sifonaje ha sido evaluado recientemente en un estudio prospectivo aleatorizado en una serie de 40 pacientes con una edad media de tres meses y medio de edad en el momento de la cirugía: en este estudio los autores aprueban el uso de estos sistemas al no asociarse de forma significativa con mayores tasas de obstrucción o infección del sistema aunque sí se mostraron capaces de prevenir la aparición de fenómenos de sobredrenaje ${ }^{35}$.

\section{Recomendaciones del grupo de trabajo}

El objetivo fundamental de la presente revisión es proporcionar un resumen actualizado de los principales aspectos diagnósticos y terapéuticos de la hidrocefalia poshemorrágica asociada a la prematuridad. Las conclusiones que se pueden formular a tenor de dicha información son en ocasiones inmediatas, ya que se originan de estudios controlados bien diseñados y con una notable potencia. En la mayoría de los casos, no obstante, provienen de información fragmentada de series no controladas descriptivas a menudo retrospectivas sujetas a un número variable de sesgos y difícilmente extrapolables a la población de la que es objeto el presente estudio. Por este motivo, las pautas que a continuación se presentan deben ser matizadas y discutidas en cada caso concreto. Sin perjuicio de lo anterior, y como paso previo a la elaboración de un protocolo común de diagnóstico y tratamiento de la hidrocefalia poshemorrágica asociada a la prematuridad, el Grupo de Trabajo de Neurocirugía Pediátrica de la Sociedad Española de Neurocirugía propone las siguientes recomendaciones:

1. La ecografía se considera la prueba de imagen de elección en el cribado, diagnóstico y seguimiento inicial de los recién nacidos pretérmino con hemorragia de matriz germinal. El estudio en modo Doppler de la dinámica del LCR y del índice de resistencia vascular puede ser útil para establecer el diagnóstico diferencial (fundamentalmente con la ventriculomegalia ex vacuo) y para evaluar de forma indirecta la compliance cerebral y la presencia de hipertensión intracraneal.

2. Ningún tratamiento farmacológico ha demostrado ser útil para disminuir la incidencia de hidrocefalia pos- 
hemorrágica en estos pacientes. El uso de acetazolamida y furosemida con este fin está contraindicado por asociar un número importante de efectos secundarios. La administración intraventricular de fibrinolíticos (protocolo DRIFT) tampoco evita la progresión de la hidrocefalia y se asocia a un número importante de complicaciones, en particular en términos de hemorragia cerebral. No obstante, su uso podría mejorar la función cognitiva a largo plazo.

3. Los sistemas de diversión transitoria de LCR (incluyendo las punciones evacuadoras) no previenen el desarrollo de la hidrocefalia y se asocian de forma significativa a una mayor incidencia de complicaciones infecciosas, por lo que no son recomendados como medida de tratamiento. En pacientes de muy bajo peso -por debajo de los 1500 gramos en el momento de la cirugía- su uso puede estar justificado con el fin de diferir la implantación de un sistema definitivo hasta un punto en que la situación general del paciente sea más favorable. Los reservorios ventriculares de LCR son probablemente los dispositivos de elección en este escenario al asociarse a una menor incidencia de complicaciones, si bien las punciones lumbares o ventriculares evacuadoras pueden resultar medidas suficientes en determinadas circunstancias.

4. La derivación permanente de LCR es la única medida de eficacia contrastada en el tratamiento inicial de la hidrocefalia poshemorrágica del prematuro. Los sistemas de derivación ventriculoperitoneal son los que ofrecen una relación riesgo-beneficio más favorable. El momento de la cirugía viene determinado por la gravedad de la hidrocefalia, el peso y la situación general del paciente, y las característica citológicas del LCR. La ventriculostomía premamilar endoscópica puede tener un papel importante en la revisión de la malfunción valvular a partir de los 6 meses de vida, pero no se recomienda como medida inicial de tratamiento. La endoscopia es una medida fundamental de tratamiento en casos de tabicación y compartimentalización del sistema ventricular.

5. La incidencia de infección de la DVP en los pacientes prematuros es particularmente alta, por lo que debe recomendarse la profilaxis antibiótica en este tipo de intervenciones. Dicha profilaxis debe concretarse de acuerdo a la flora microbiológica específica de cada centro, prestando especial atención a la incidencia de infecciones por estafilocos resistentes a meticilina.

6. El empleo de una técnica quirúrgica especialmente cuidadosa es un aspecto esencial en el tratamiento de estos pacientes y su importancia debe ser subrayada. El acceso ventricular frontal no se ha asociado de forma significativa a una menor incidencia de obstrucción proximal respecto al acceso parietal. De forma análoga, la guía mediante ecografía o endoscopia en la implantación del catéter ventricular no se asocia a una disminución en la incidencia de malfunción proximal respecto a la implantación no asistida. La introducción del catéter distal mediante minilaparotomía puede disminuir el número de complicaciones abdominales respecto a la punción con trócar, particularmente en pacientes con antecedentes de enterocolitis necrotizante. La introducción de una longitud de catéter redundante (e.g. $50 \mathrm{~cm}$ de catéter intra-abdominal) disminuye la necesidad de revisiones distales y no parece asociarse a una mayor incidencia de complicaciones. Tradicionalmente los sistemas de derivación empleados han sido los sistemas de presión diferencial de baja o media presión. Los sistemas de derivación de control de flujo, las válvulas programables o los dispositivos antigravitatorios podrían ofrecer ventajas desde el punto de vista hidrodinámico. Los sistemas de pequeño tamaño y bajo perfil pueden prevenir la aparición de complicaciones cutáneas locales. El conocimiento preciso de la situación hidrodinámica del paciente y de las características técnicas de los sistemas valvulares son requisitos indispensables en la elección apropiada del dispositivo de derivación de LCR más conveniente.

\section{Bibliografía}

1. Adcock, L.M., Moore, P.J., Schlesinger, A.E. et al.: Correlation of ultrasound with postmortem neuropathologic studies in neonates. Pediatr Neurol 1998;19: 263-271.

2. Albright, A., Haines, S., Taylor, F.: Function of parietal and frontal shunts in childhood hydrocephalus. J Neurosurg 1988; 69: 883-886.

3. Ammirati, M., Raimondi, A.J.: Cerebrospinal fluid shunt infections in children. A study on the relationship between the etiology of hydrocephalus, age at the time of shunt placement, and infection rate. Childs Nerv Syst. 1987; 3: 106-109.

4. Arnell, K., Cesarini, K., Lagerqvist-Widh, A., Wester, T., Sjölin, J.: Cerebrospinal fluid shunt infections in children over a 13-year period: anaerobic cultures and comparison of clinical signs of infection with Propionibacterium acnes and with other bacteria. J Neurosurg Pediatr 2008; 1: 366-372.

5. Berger, A., Weninger, M., Reinprecht, A., Haschke, N., Kohlhauser, C., Pollak, A.: Long-term experience with subcutaneously tunneled external ventricular drainage in preterm infants. Childs Nerv Syst. 2000; 16: 103-109.

6. Bergman, I., Wald, E.R., Meyer, J.D., Painter, M.J.: Epidural abscess and vertebral osteomyelitis following serial lumbar punctures. Pediatrics 1983; 72: 476-480.

7. Boop, F.A.: Posthemorrhagic Hydrocephalus of Prematurity. En: Cinalli G, Maixner WJ, Sainte-Rose (eds), Peditric Hydrocephalus. Springer-Verlag Italia, Milano 2004.pp 121131.

8. Bierbrauer, K.S., Storrs, B.B., McLone, D.G., Tomita, T., Dauser, R.: A prospective, randomized study of shunt function and infections as a function of shunt placement. Pediatr Neurosurg. 1990-1991;16: 287-291.

9. Boynton Boynton, B.R., Boynton, C.A., Merritt, T.A., 
Vaucher, Y.E., James, H.E., Bejar, R.F.: Ventriculoperitoneal shunts in low birth weight infants with intracranial hemorrhage: neurodevelopmental outcome. Neurosurgery. 1986; 18 : 141-145.

10. Bruinsma, N., Stobberingh, E.E., Herpers, M.J., Vles, J.S., Weber, B.J., Gavilanes, D.A.: Subcutaneous ventricular catheter reservoir and ventriculoperitoneal drain-related infections in preterm infants and young children. Clin Microbiol Infect. 2000; 6: 202-206.

11. Brydon, H.L., Bayston, R., Hayward, R., Harkness, W.: The effect of proteins and blood cells on the flow-pressure characteristics of shunts. Neurosurgery 1996; 38: 498-504.

12. Couldwell, W., LeMay, D., Gordon, J.: Experience with use of extended length peritoneal shunt catheters. J Neurosurg 1996; 85: 425-427.

13. Couture, A., Veyrac, C., Baud,, C., Saguintaah, M., Ferran, J.L.: Avanced cranial ultrasound: transfontanellar Doppler imaging in neonates. Eur Radiol. 2001;11: 23992410.

14. Choux, M., Genitori, L., Lang, D., Lena, G.: Shunt implantation: reducing the incidence of shunt infection. J Neurosurg. 1992; 77: 875-880.

15. Dan, N.G., Wade, M.J.: The incidence of epilepsy after ventricular shunting procedures. J Neurosurg. 1986; 65: 1921.

16. Drake, J., Kestle, J., Milner, R., et al.: Randomized trial of cerebrospinal fluid shunt valve design in pediatric hydrocephalus. Neurosurgery 1998; 43: 294-305.

17. Enger, P.O., Svendsen, F., Wester, K.: CSF shunt infections in children: experiences from a population-based study. Acta Neurochir (Wien). 2003; 145: 243-248.

18. Enriquez, G., Correa, F., Aso, C., Carreño, J.C., Gonzalez, R., Padilla, N.F., Vazquez, E.: Mastoid fontanelle approach for sonographic imaging of neonatal brain. Pediatr Radiol. 2006; 36: 532-540.

19. Fanaroff, A.A., Stoll, B.J., Wright, L.L., Carlo, W.A., Ehrenkranz, R.A., Stark, A.R., Bauer, C.R., Donovan, E.F., Korones, S.B., Laptook, A.R., Lemons, J.A., Oh, W., Papile, L.A., Shankaran, S., Stevenson, D.K., Tyson, J.E., Poole, W.K.: NICHD Neonatal Research Network. Trends in neonatal morbidity and mortality for very low birthweight infants. Am J Obstet Gynecol. 2007; 196:147. e 1-8.

20. Goh, D., Minns, R.A., Hendry, G.M.A., Thambyayah, M., Steers, A.J.W..: Cerebrovascular resistive index assessed by Duplex Doppler sonography and its relationship to intracranial pressure in infantile hydrocephalus. Pediatr Radiol 1992; 22: 246-250.

21. Goldstein, G.W., Chaplin, E.R., Maitland, J., Norman, D.: Transient hydrocephalus in premature infants: Treatment by lumbar punctures. Lancet 1976; 1: 512-514.

22. Gurtner, P., Bass, T., Gudeman, S.K., et al.: Surgical management of posthemorrhagic hydrocephalus in 22 lowbirth-weight infants. Childs Nerv Syst 1992; 8: 198-202.
23. Greenberg, M.S.: Hydrocephalus. En: Handbook of neurosurgery, $7^{\mathrm{a}}$ ed. Pp 307-337 Thieme, Suttgart, Germany.

24. Gyorgy, I.: Neonatal intracranial haemorrhage. Aspiration trough anterior fontanel in 23 cases. Acta Paediatr Acad Sci Hung 1981; 22: 347-352,

25. Haines, S.J., Walters, B.C.: Antibiotic prophylaxis for cerebrospinal fluid shunts: a metanalysis. Neurosurgery. 1990; 34: 87-92.

26. Hanlo, P.W., Cinalli, G., Vandertop, W.P., Faber, J.A., Bøgeskov, L., Borgesen, S.E., Boschert, J., Chumas, P., Eder, H., Pople, I.K., Serlo, W., Vitzthum, E.: Treatment of hydrocephalus determined by the European Orbis Sigma Valve II survey: a multicenter prospective 5-year shunt survival study in children and adults in whom a flow-regulating shunt was used. J Neurosurg. 2003; 99: 52-57.

27. Hansen, A.R., DiSalvo, D., Kazam, E., Allred, E.N., Leviton, A.: Sonographically detected subarachnoid hemorrhage: an independent predictor of neonatal posthemorrhagic hydrocephalus? Clin Imaging. 2000; 24:121-129.

28. Horinek, D., Cihar, M., Tichy, M.: Current methods in the treatment of posthemorrhagic hydrocephalus in infants. Bratisl Lek Listy, 2003; 104: 347-351.

29. Hudgins, R.J., Boydston, W.R., Gilreath, C.L.: Treatment of posthemorrhagic hydrocephalus in the preterm infant with a ventricular access device. Pediatr Neurosurg 1998; 29: 309-313.

30. Jain, H., Sgouros, S., Walsh, A.R., Hockley, A.D.: The treatment of infantile hydrocephalus: "differential-pressure" or "flow-control" valves. A pilot study. Childs Nerv Syst. 2000; 16: 242-246.

31. Kaske, T.I., Rumack, C.M., Harlow, C.L.: Radiología del cerebro del recién nacido y el lactante. En Rumack CM, Wilson SR, Chaborneau JW. Diagnóstico por ecografía. Vol 2. $2^{\mathrm{a}}$ ed en español, de Diagnostic Ultrasound. Madrid: Marban SL. 1999; p.1443-1501.

32. Kazam, E., Rudelli, R., Monte, W., Rubenstein, W.A., Ramirez, E., Kairam, R., Paneth, N.: Sonographic diagnosis of cisternal subarachnoid hemorrhage in the premature infant. AJNR Am J Neuroradiol. 1994; 15: 1009-1020.

33. Kennedy, C.R., Ayers, S., Campbell, M.J., Elbourne, D., Hope, P., Johnson, A.: Randomized controlled trial of acetazolamide and furosemide in posthemorrhagic ventricular dilation in infancy: follow-up at 1 year. Pediatrics 2001; 108: 597-607

34. Kestle, J.R.W., Drake, J.M., Cochrane, D.D., et al.: Lack of benefit of endoscopic ventriculoperitoneal shunt insertion: A multicenter randomized trial. J Neurosurg 2003; 98: 284-290.

35. Khan, R.A., Narasimhan, K.L., Tewari, M.K., Saxena, A.K.: Role of shunts with antisiphon device in treatment of pediatric hydrocephalus. Clin Neurol Neurosurg. 2010; 112: 687-690.

36. Kuban, K., Sanocka, U., Leviton, A., Allred, E.N., 
Pagano, M., Dammann, O., Share, J., Rosenfeld, D., Abiri, M., DiSalvo, D., Doubilet, P., Kairam, R., Kazam, E., Kirpekar, M., Schonfeld, S.: White matter disorders of prematurity: association with intraventricular hemorrhage and ventriculomegaly. The Developmental Epidemiology Network.J Pediatr. 1999; 134: 539-546.

37. Lam, H.P., Heilman, C.B.: Ventricular access device versus ventriculosubgaleal shunt in post hemorrhagic hydrocephalus associated with prematurity. J Matern Fetal Neonatal Med, 2009; 21: 1097-1101,

38. Levene, M.I.: Measurement of the growth of the lateral ventricles in preterm infants with real-time ultrasound. Arch Dis Child. 1981; 56: 900-904.

39. Levene, M.I.: Ventricular tap under direct ultrasound control. Arch Dis Child 1982; 57: 873-875.

40. Levene, M.I., de Vries, L.: Extension of neonatal intraventricular hemorrhage. Arch Dis Child 1984; 59: 631636.

41. Lima, M.M.M., Pereira, C.U., Silva, A.M.: Ventriculoperitoneal shunt infections in children and adolescents with hydrocephalus. Arq Neuro-Psiquiatr 2007; 65: $118-123$.

42. Lipina, R., Reguli, S., Novacková, L., Podesvová, H., Brichtová, E.: Relation between TGF- $\beta 1$ level in cerebrospinal fluid and ETV outcome in premature newborns with posthemorrhagic hydrocephalus. Childs Nerv Syst 2010; 26: 333-341.

43. Luciano, R., Velardi, F., Romagnoli, C., Papacci, P., De Stefano, V., Tortorolo, G.: Failure of fibrinolytic endoventricular treatment to prevent neonatal post-haemorrhagic hydrocephalus. Childs Nerv Syst 1997, 13: 73-76.

44. Martínez-Lage, J.F., Almagro, M.J., Del Rincón, I.S., Pérez-Espejo, M.A., Piqueras, C., Alfaro, R., Ros de San Pedro, J.: Management of neonatal hydrocephalus: feasibility of use and safety of two programmable (Sophy and Polaris) valves. Childs Nerv Syst. 2008; 24: 549-556.

45. McComb, J.G., Ramos, A.D., Platzer, A.C., et al.: Management of hydrocephalus secondary to intraventricular hemorrhage in the preterm infant with a subcutaneous ventricular catheter reservoir. Neurosurgery 1983; 13: 295300 .

46. McGirt, M.J., Leveque, J., Wellons, J.C., et al.: Cerebrospinal fluid shunt survival and etiology of failures: a sevenyear institutional experience. Pediatr Neurosurg 2002; 36: $248-255$.

47. McMenamin, J.B., Shackelford, G.D., Volpe, J.J.: Outcome of neonatal intraventricular hemorrhage with periventricular echodense lesions. Ann Neurol. 1984; 15: 285 290.

48. Ment, L.R., Bada, H.S., Barnes, P., Grant, P.E., Hirtz, D., Papile, L.A., Pinto-Martin, J., Rivkin, M., Slovis, T.L.: Practice parameter: Neuroimaging of the neonate: Report of the Quality Standars Subcommittee of the American Academy of Neurology and the Practice Committee of the Child Neurology Society. Neurology. 2002; 58: 1726-1738.

49. Mirmiran, M., Barnes, P.D., Keller, K., Constantinou, J.C., Fleisher, B.E., Hintz, S.R. et al.: Neonatal brain magnetic resonance imaging before discharge is better than serial cranial ultrasound in predicting cerebral palsy in very low birthweight preterm infants. Pediatrics 2004; 11: 992-998.

50. Müller, W., Urlesberger, B., Naurer, U., et al.: Serial lumbar tapping to prevent posthaemorrhagic hydrocephalus after intracranial haemorrhage in preterm infants. Wien Klin Wochenschr 1998; 110: 631-634.

51. Nejat, F., Tajik, P., El Khashad, M., et al.: A randomized trial of ceftriaxone versus trimethropim-sulfamethoxazole to prevent ventriculoperitoneal shunt infection. J Microbiol Immunol Infect 2008; 41: 112-117.

52. Nishimaki, S., Iwasaki, Y., Akamatsu, H.: Cerebral blood flow velocity before and after cerebrospinal fluid drainage in infants with posthemorrhagic hydrocephalus. J Ultrasound Med. 2004; 23: 1315-1319.

53. Notarianni, C., Vannemreddy, P., Caldito, G., Bollam, P., Wylen, E., Willis, B., Nanda, A.: Congenital hydrocephalus and ventriculoperitoneal shunts: influence of etiology and programmable shunts on revisions. Neurosurg Pediatr. 2009; 4: $547-552$.

54. Paneth, N., Pinto Martin, J., Gardiner, J.: Incidence and timing of intraventricular hemorrhage in low birth weight infants. Am J Epidemiol 1993; 137: 1167-1176.

55. Pape, K.E., Blackwell, R.J., Cusick, G.: Ultrasound detection of brain damage in preterm infants. Lancet 1979; 1 : 1261-1264.

56. Papile, L.A., Burstein, J., Burstein, R., Koffler, H.: Incidence and evolution of subependymal and intraventricular hemorrhage: a study of infants with birth weights less than 1,500 gm. J Pediatr. 1978; 92: 529-534.

57. Papile, L.A., Munsick-Bruno, G., Schaefer, A.: Relationship of cerebral intraventricular hemorrhage and early childhood neurological handicaps. J Pediatr 1983; 103: 273277.

58. Patridge, J.C., Babcock, D.S., Steichen, J.J.: Optimal timing for diagnostic cranial ultrasound in low-birthweight infants: detection of intracranial hemorrhage and intraventricular dilatation. J Pediatr 1983; 102: 281-287.

59. Peretta, P., Ragazzi, P., Carlino, C.F., Gaglini, P., Cinalli, G.: The role of Ommaya reservoir and endoscopic third ventriculostomy in the management of post-hemorrhagic hydrocephalus of prematurity. Childs Nerv Syst 2007; 23: 765-771.

60. Perlmann, J.M., Volpe, J.J.: Cerebral blood flow velocity in relation to intraventricular hemorrhage in the premature newborn infant. J Pediatr 1982; 100: 956-959.

61. Philip, A.G., Allan, W.C., Tito, A.M., Wheeler, L.R.: Intraventricular hemorrhage in preterm infants: declining incidence in the 1980s. Pediatrics. 1989; 84: 797-801. 
62. Pollack, I., Albright, A., Adelson, P.: Group H-MI. A randomized, controlled study of a programmable shunt valve versus a conventional valve for patients with hydrocephalus. Neurosurgery 1999; 45: 1399-411.

63. Rahman, S., Teo, C., Morris, W., et al.: Ventriculosubgaleal shunt: A treatment option for progressive posthemorrhagic hydrocephalus. Childs Nerv Syst 1995; 11: 650-654.

64. Ratilal, B., Costa, J., Sampaio, C.: Antibiotic prophylaxis for surgical introduction of intracranial ventricular shunts: a systematic review. J Neurosurg Pediatrics. 2008; 1 : 48-5610. 9.

65. Rehman, A.U., Rehman, T.U., Bashir, H.H., Gupta, V.: A simple method to reduce infection of ventriculoperitoneal shunts. J neurosurg Pediatrics 2010; 5: 569-572.

66. Reinprecht, A., Dietrich, W., Berger, A., Bavinzski, G., Weninger, M., Czech, T.: Posthemorrhagic hydrocephalus in preterm infants: long-term follow-up and shunt-related complications. Childs Nerv Syst. 2001; 17: 663-669.

67. Rhodes, T.T., Edwards, W.H., Saunders, R.L., et al.: External ventricular drainage for initial treatment of neonatl posthemorrhagic hydrocephalus: Surgical and neurodevelopmental outcomes. Pediatr Neurosci 1987; 13: 255-262.

68. Ros-López, B., Jaramillo-Dallimonti, A.M., De MiguelPueyo, L.S., Rodriguez-Barceló, S., Domínguez-Paez, M., Ibañez-Botella, G., Márquez-Márquez, B., Arráez-Sanchez, M.A.: Hemorragia intravetricular en el prematuro e hidrocefalia post-hemorrágica. Propuesta de un protocolo de manejo basado en la derivación ventricular precoz. Neurocirugía. 2009; 20: 15-24.

69. Shackelford, G.D., Volpe, J.J.: Cranial ultrasonography in the evaluation of neonatal intracranial hemorrhage and its complications. J Perinat Med 1985; 13: 293-304.

70. Shah, S.S., Hall, M., Slonim, A.D., Hornig, G.W., Berry, J.G., Sharma, V.: A multicenter study of factors influencing cerebrospinal fluid shunt survival in infants and children. Neurosurgery. 2008; 62: 1095-1102.

71. Sheth, R.D.: Trends in incidence and severity of intraventricular hemorrhage. J Child Neurol. 1998; 13: 261264.

72. Shinnar, S., Gammon, K., Bergman, E.W.Jr., Epstein, M., Freeman, J.M.: Management of hydrocephalus in infancy: use of acetazolamide and furosemide to avoid cerebrospinal fluid shunts. J Pediatr 1985; 107: 31-37.

73. Shooman, D., Portess, H., Sparrow, O.: A review of the current Treatment methods for posthaemorrhagic hydrocephalus of infants. Cerebrospinal Fluid Res 2009; 30; 6: 1.

74. Siegel, M.: Cerebro. Capítulo 3. En Siegel M. Ecografía pediátrica. Ed en español de Pediatric sonography, $2^{\text {nd }}$ ed. Madrid: Marban SL. 2004. p.41-121.

75. Silverboard, G., Horder, M.H., Ahmann, P.: Reliability of ultrasound in diagnosis of intracerebral hemorrhage and poshemorrhagic hydrocephalus: comparision with computed tomography. Pediatrics 1980; 66: 507-514.
76. Simon, G.: Neonatal ventricular haemorrhage: Treatment by puncture. Acta Paediatr Hung 1985; 26: 281-287.

77. Simon, T.D., Hall, M., Riva-Cambrin, J., Albert, J.E., Jeffries, H.E., Lafleur, B., Dean, J.M., Kestle, J.R.: Hydrocephalus Clinical Research Network. Infection rates following initial cerebrospinal fluid shunt placement across pediatric hospitals in the United States. J Neurosurg Pediatr. 2009; 4: 156-165.

78. Sklar, F., Adegbite, A., Shapiro, K., Millar, K.: Ventriculosubgaleal shunt: Management of posthemorrhagic hydrocephalus in premature infants. Pediatr Neurosurg 1992; 18 : 263-265.

79. Smith, K.M., Deddish, R.B., Ogata, E.S.: Meningitis associated with serial lumbar punctures and post-hemorrhagic hydrocephalus J Pediatrics 1986; 109: 1057-1060.

80. Stamos, J.K., Kaufman, B.A., Yogev, R.: Ventriculoperitoneal shunt infections with gram-negative bacteria. Neurosurgery. 1993; 33: 858-862.

81. Taylor, A.G., Peter, J.C.: Advantages of delayed VP shunting in posthaemorrgagic hydrocephalus seen in lowweight infants. Childs Nerv Syst 2001; 17: 328-333.

82. Taylor, G.A., Phillips, M.D., Ichord, R., Carson, B.S., Gates, J.A., James, C.S.: Intracranial compliance in infants: evaluation with doppler US. Pediatr Radiol. 1994; 191: 787791.

83. Taylor, G.A., Madsen, J.R.: Neonatal hydrocephalus: Hemodynamic response to fontanelle compression. Correlation with intracranial pressure and need for shunt placement. Pediatr Radiol. 1996; 201: 685-689.

84. Taylor, G.A.: Sonographic assessment of posthemorrhagic ventricular dilatation. Radiol Clin North Am. 2001; 39: 541-551.

85. Tortorolo, G., Luciano, R., Papacci, P., Tonelli, T.: Intraventricular hemorrhage: past, present and future, focusing on classification, pathogenesis and prevention. Childs Nerv Syst. 1999; 15: 652-661.

86. Venes, J.L., Dauser, R.C.: Epilepsy following ventricular shunt placement. J Neurosurg. 1987; 66: 154-155.

87. Ventriculomegaly trial group: Randomised trial of early tapping in neonatal posthaemorrhagic ventricular dilatation. Arch Dis Child 1990; 65: 3-10.

88. Ventriculomegaly Group: Randomised trial of early tapping in neonatal posthaemorrhagic ventricular dilatation: results at 30 months. Arch Dis Child Fetal Neonatal Ed 1994; 70: F129-136.

89. Veyrac, C., Couture, A., Saguintaah, M., Baud, C.: Brain ultrasonography in the premature infant. Pediatr Radiol. 2006; 36: 626-635.

90. Vinchon, M., Lapeyre, F., Duquennoy, C., Dhellemmes, P.: Early treatment of posthemorrhagic hydrocephalus in low-birth-weight infants with valveless ventriculoperitoneal shunts. Pediatr Neurosurg. 2001; 35: 299-304.

91. Volpe, J.J.: Brain injury in the premature infant: over- 
view of clinical aspects, neuropathology and pathogenesis. Semin Pediatr Neurol 1998; 5: 135-151.

92. Volpe, J.J.: Intracranial hemorrhage: germinal matrixintraventricular hemorrhage of the premature infant. En: Neurology of the newborn, $4^{\text {th }}$ ed. Philadelphia: W.B. Saunders, 2001, p 451.

93. Vural, M., Yilmaz, I., Ilikkan, B., Erginoz, E., Perk, Y.: Intraventricular hemorrhage in preterm newborns: risk factors and results from a University Hospital in Istanbul, 8 years after.Pediatr Int. 2007; 49: 341-344.

94. Walters, B.C., Goumnerova, L., Hoffman, H.J. et al.: A randomized controlled trial of perioperative rifampicin/ trimetroprim in cerebrospinal fluid shunt surgery. Child Nerv Syst 1992; 8: 253-257.

95. Wellons, J.C., Shannon, C.N., Kulkarni, A.V., Simon, T.D., Riva-Cambrin, J., Whitehead, W.E., Oakes, W.J., Drake, J.M., Luerssen, T.G., Walker, M.L., Kestle, J.R.: Hydrocephalus Clinical Research Network. A multicenter retrospective comparison of conversion from temporary to permanent cerebrospinal fluid diversion in very low birth weight infants with posthemorrhagic hydrocephalus. J Neurosurg Pediatr. 2009; 4: 50-55.

96. Whitehead, W.E., Jea, A., Vachhrajani, S., Kulkarni, A.V., Drake, J.M.: Accurate placement of cerebrospinal fluid shunt ventricular catheters with real-time ultrasound guidance in older children without patent fontanelles. J Neurosurg. 2007; 107 (5 Suppl): 406-410.

97. Whitelaw, A.: Intraventricular haemorrhage and posthaemorrhagic hydrocephalus: pathogenesis, prevention and future interventions. Semin Neonatol 2001; 6: 135-146.

98. Whitelaw, A.: Repeated lumbar or ventricular punctures in newborns with intraventricular hemorrhage. Cochrane Database Syst Rev 2001; (1): CD000216, .

99. Whitelaw, A.: Intraventricular streptokinase after intraventricular hemorrhage in newborn infants. Cochrane Database Syst Rev. 2001; (1): CD000498.

100. Whitelaw, A., Kennedy, C.R., Brion, L.P.: Diuretic therapy for newborn infants with posthemorrhagic ventricular dilatation. Cochrane Database Syst Rev 2001; (1) CD002270.

101. Whitelaw, A., Thoresen, M., Pople, I.: Posthaemorr-

\section{Comentario al trabajo Hidrocefalia poshemorrágica aso- ciada a la prematuridad: evidencia disponible diagnóstica y terapéutica de C. Bravo y cols.}

Este trabajo constituye un esfuerzo coordinado del Grupo de Neurocirugía Pediátrica de la Sociedad Española de Neurocirugía, por el que los autores deben ser felicitados. No hay más que observar la cantidad de bibliografía manejada para comprender la enorme meticulosidad del trabajo. Aunque la hidrocefalia es frecuentemente relegada hagic ventricular dilatation. Arch Dis Child Fetal Neonatal Ed 2002; 86: F72-74.

102. Whitelaw, A., Pople, I., Cherian, S., Evans, D., Thoresen, M.: Phase 1 Trial of Prevention of hydrocephalus after intraventricular hemorrhage in newborn infants by drainage, irrigation and fibrinolytic therapy. Pediatrics 2003; 111: 759-765.

103. Whitelaw, A., Evans, D., Carter, M., et al.: Randomized Clinical Trial of Prevention of Hydrocephalus After Intraventricular Hemorrhage in Preterm Infants: BrainWashing versus Tapping Fluid. Pediatrics 2007; 119: 10711078.

104. Whitelaw, A., Jary, S., Kmita, G., Wroblewska, Jet al.: Randomized trial of drainage, irrigation and fibrinolytic therapy for premature infants with posthemorrhagic ventricular dilatation: developmental outcome at 2 years. Pediatrics. 2010; 125: e852-858.

105. Willis, B.K., Kumar, C.R., Wylen, E.L., Nanda, A.: Ventriculosubgaleal shunts for posthemorrhagic hydrocephalus in premature infants. Pediatr Neurosurg 2005; 4: 178-185.

106. Willis, B., Javalkar, V., Vannemreddy, P., et al.: Ventricular reservoirs and ventriculoperitoneal shunts for premature infants with posthemorrhagic hydrocephalus: an institutional experience. J Neurosurg Pediatrics 2009; 3: 94100.

107. Winkler, P.: Colour-coded echographic flow imaging and spectral analysis of cerebrospinal fluid (CSF) in meningitis and hemorrhage. Pediatr radiol. 1992; 22: 24-30.

108. Zuerrer, M., Martin, E., Bolsthauser, E.: MR imaging of intracranial hemorrhage in neonates and infants at 2.35 Tesla. Neuroradiology 1991; 33: 223-229.

Bravo, C.; Cano, P.; Conde, R.; Gelabert, M.; Pulido, P.; Ros, B.; Miranda, P.: Hidrocefalia poshemorrágica asociada a la prematuridad: evidencia disponible diagnóstica y terapéutica. Neurocirugía 2011; 22: 381-400.

Correspondencia: Pablo Miranda. Servicio de Neurocirugía Hospital Universitario y Politécnico La Fe Bulevar Sur s/n 46026 Valencia.

mirandalloret@gmail.com a manos poco experimentadas, la patología que tratan los autores es complicada y su manejo terapéutico está lejos de estar consensuado. Con el permiso del Editor quisiera hacer unas breves observaciones. 1. Sin ningún género de dudas, la ecografía transfontanelar constituye hoy en día la técnica diagnóstica de elección, por razones de inocuidad, fiabili- 
dad, economía y facilidad de realización y de repetición. En nuestro hospital las ecografías se realizan a pie de cuna, de forma rutinaria, tanto en la UCI Neonatal como en los boxes de Neonatología. 2. En mi opinión, es conveniente descartar la presencia de una ventriculitis antes de proceder a colocar una válvula, ya que las imágenes de las paredes ventriculares en la hemorragia y en la infección ventricular vistas mediante ecografía pueden ser confusas. De ahí la conveniencia de realizar una punción lumbar, o mejor ventricular, para descartar una infección ventricular antes de implantar la válvula. 3. La revisión que realizan los autores sobre la secuencia de actuaciones antes de colocar la válvula es completa y está totalmente razonada (punciones, reservorio, drenaje ventricular etc.). 4. Otros aspectos, como el momento de colocación de la derivación del LCR, y el tipo de válvula siguen siendo objeto de debate como se puede comprobar en los diversos estudios publicados sobre el tema. Nuestras preferencias están del lado de las válvulas programables, aún en prematuros, ya que en nuestra experiencia, aunque no ha descendido el número de obstrucciones del catéter ventricular, sí que han disminuido las revisiones quirúrgicas debidas a drenaje insuficiente o excesivo. 5. Esperamos que este Grupo de Trabajo se ponga pronto manos a la obra y realice el estudio cooperativo de cuyos resultados estaremos pendientes.

J.F. Martínez-Lage Murcia 